\title{
Review and Comparison of Grid-Tied Inverter Controllers in Microgrids
}

\author{
Qing Liu*, Student Member, IEEE, Tommaso Caldognetto*†, Member, IEEE, Simone Buso*, Member, IEEE
}

\begin{abstract}
Grid-tied inverters are widely used for interfacing renewable energy sources or storage devices to low-voltage electrical power distribution systems. Lately, a number of different control techniques have been proposed to address the emerging requirements of the smart power system scenario, in terms of both functionalities and performance. This paper reviews the techniques proposed for the implementation of current-controlled or voltagecontrolled inverters in microgrids. By referring to a voltage source inverter with $L C L$ output filter, the different control architectures are classified as single-, double-, and tripleloop. Then, the functionalities that are needed or recommended in the grid-connected, islanded, and autonomous operating modes of the grid-tied inverter are identified and their implementation in the different control structures is discussed. To validate the analysis and to better illustrate the merits and limitations of the most effective solutions, six control strategies are finally implemented and experimentally compared on a single-phase, grid-connected inverter setup.
\end{abstract}

Index Terms-dc-ac; inverter controllers; grid-tied inverter; microgrids; multi-loop control; review; zero-level control.

\section{INTRODUCTION}

$\mathbf{R}$ ECENT years witnessed the integration of a variety of small-scale distributed energy resources (DER) and energy storage systems (ESS) into the traditional, centralized, electrical energy distribution grids [1]. This trend is accelerating the transition of low-voltage electrical power networks towards the smart microgrid paradigm, namely, an efficient, synergic, and reliable interconnection of loads, DERs, and ESSs, possibly connected with a typically larger, upstream grid at a point of common coupling (PCC). Fig. 1 displays a representative scenario, where electronic power converters are diffusely applied as an interface among different electrical domains. In particular, grid-tied inverters are used to interface with the ac-grid simple dc-sources or more complex systems of energy resources and loads that may compose, by themselves, small dc microgrids, often referred to as nanogrids [2].

A peculiarity of smart microgrids is to be controllable, dispatchable, and flexible power systems, that can operate connected (i.e., $\mathrm{SW}_{2}$ closed in Fig. 1) as well as disconnected

Manuscript received June 11, 2019; revised September 30, 2019; accepted November 24, 2019.

Qing Liu and Simone Buso are with the Department of Information Engineering, University of Padova, Padova, 35131, Italy (email: qing.liu@dei.unipd.it; simone.buso@dei.unipd.it). Tommaso Caldognetto (corresponding author) is with the Department of Management and Engineering and with the Interdepartmental Centre Giorgio Levi Cases, University of Padova, Vicenza, 36100, Italy (e-mail: tommaso.caldognetto@unipd.it). (i.e., $\mathrm{SW}_{2}$ open) from the upstream grid. In general terms, three different operation modes can be distinguished based on the state of the switches $\mathrm{SW}_{1}$ and $\mathrm{SW}_{2}$, which are controlled locally by the inverter or remotely by, for example, the distribution system operator (DSO), respectively. In this paper, the three operation modes are referred to as:

- Grid-tied mode: $\mathrm{SW}_{1}$ and $\mathrm{SW}_{2}$ are both closed. The upstream grid imposes the voltage, while each grid-tied inverter behaves as a current source or a power source.

- Islanded mode: in the event of faults, disconnections may be issued by protection devices and actuated by opening line breakers, represented by $\mathrm{SW}_{2}$. Grid-tied inverters may sustain microgrid operation in this case. They are typically controlled as voltage sources, feeding ac loads connected to the PCC and maintaining the voltage of the islanded system within suitable amplitude and frequency ranges.

- Autonomous mode: grid-tied inverters may intentionally disconnect from the PCC at any time, by opening $\mathrm{SW}_{1}$, and operate autonomously, in which case they operate as controlled voltage sources feeding their local ac loads only.

In this context, grid-tied inverters play multiple roles: they couple dc and ac distribution buses, they contribute in feeding local ac loads, they deliver the energy generated by local resources to the grid, all that while complying with all the applicable regulation standards (e.g., IEEE Std. 1547-2018 [3]). To allow safe operation in the different modes and seamless transitions [4], accurate control design and good performance are crucial, especially when the upstream grid is weak. Indeed, power systems with high penetration of renewable sources often show low inertia and short circuitratios, making the voltage at the point of connection of the inverter sensitive to power flow variations. It has been shown that poor grid-stiffness significantly impairs power quality [5], limits the effectiveness of active damping [6], affects control performance of inverters [7], and degrades the stability of converter/grid connections [8]. As a result, proper operation represents quite a challenge. It has been tackled at the microgrid level by means of hierarchical control structures, composed of zero-level, primary, secondary, and tertiary control layers, as outlined in Fig. 1 [9].

The identification of effective control solutions for grid-tied inverters in the outlined scenario has aroused great interest in the research community, as proven by the copious literature on the topic. Depending on the specific control strategy at the zero-level control layer, different features can be achieved, 


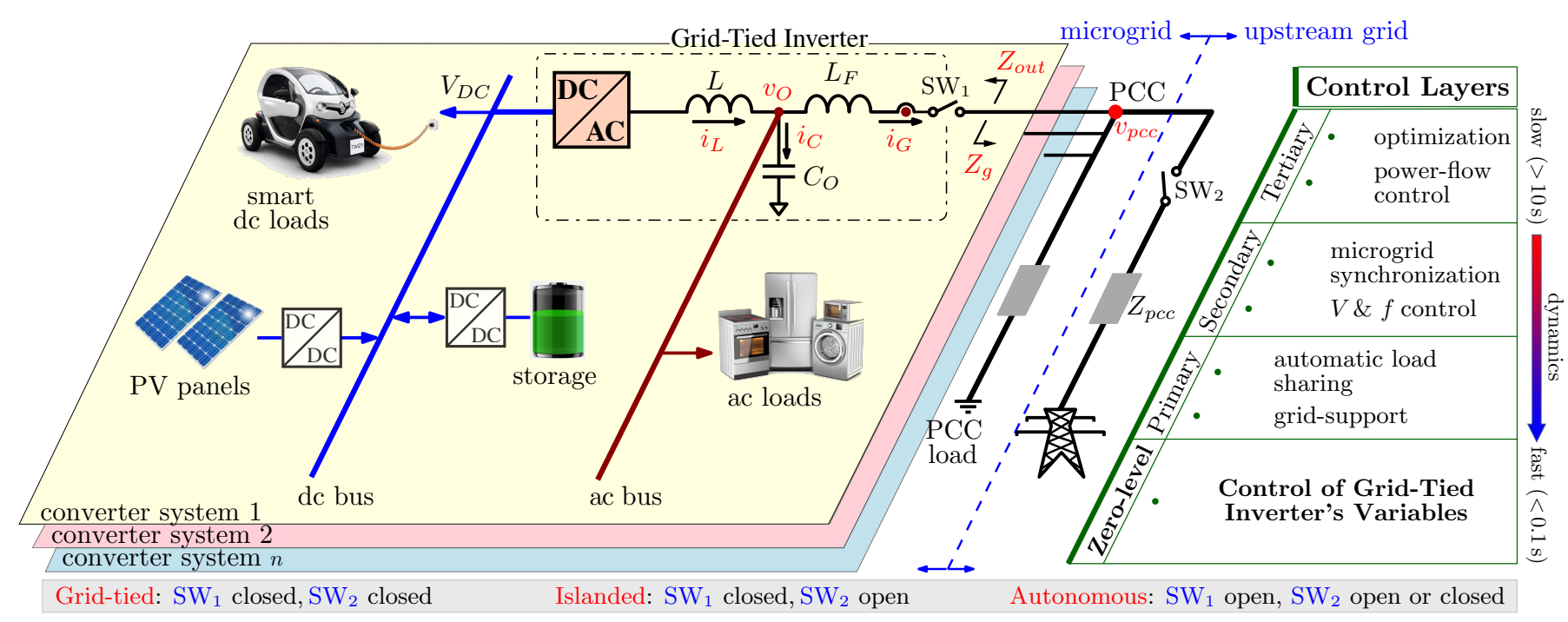

Fig. 1. Grid-tied inverter in a typical microgrid scenario. Distributed grid-tied inverters in microgrids are coordinated by control layers hierarchically organized [9]-[13], [33].

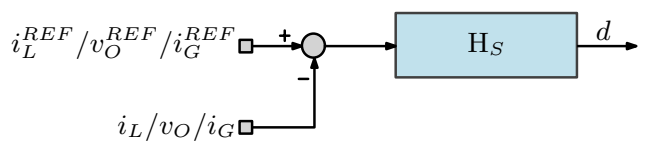

Fig. 2. Single-loop controller structure. $\mathrm{H}_{S}$ is the regulator of the considered state variable.

requiring a proper selection of the most suitable strategies to satisfy the targeted control goals [10]-[13].

This paper aims at reviewing the features of the different solutions, considering the main documented contributions and providing information that support a proper selection of the control. While review papers exist that are focused on microgrid control concepts, development trends, and expected features from a system-level perspective [14]-[28], this paper deals with the applications that can be found in the low-voltage microgrid scenario, considering the zero-level control solutions [29]-[32] presented so far. That considered, the goals of this paper can be summarized as: 1) to present a survey of control strategies for grid-tied inverters in the outlined microgrid scenario; 2) to identify the main functionalities of the gridtied inverters in the different operating modes; 3) to discuss the applicability and effectiveness of the possible control strategies in implementing the identified functionalities; and 4) to evaluate and equitably compare the performance of the most representative control strategies.

The reminder of the paper is organized as follows. In Sec. II, a comprehensive survey and classification of control strategies is presented, while the critical converter functionalities and control strategies are analyzed in Sec. III. A case study is then presented in Sec. IV, which allows to highlight the different performance offered by the most widespread control strategies. Based on that, a comparative analysis is reported based on experimental results. A brief outlook of the future trends is given in Sec. V. Conclusions are finally presented in Sec. VI.

\section{CONTROL STRATEGIES CLASSificATION}

Considering the single-phase $L C L$-filtered inverter shown in Fig. 1, six electrical variables can be identified for control: inductor current $i_{L}$, inverter-side inductor voltage $v_{L}$, capacitor current $i_{C}$, output voltage $v_{O}$, grid current $i_{G}$, and grid-side inductor voltage $v_{L_{f}}$. These variables can be divided into two groups: $i$ ) state variables, namely, $i_{L}, v_{O}$, and $i_{G}$, which can be fed-back and closed-loop controlled, so as to guarantee a specified reference tracking performance; $i$ ) auxiliary variables, including $v_{L}, i_{C}$ and $v_{L_{f}}$, which can also be fed-back, mainly in complementary loops, for the purpose of improving control performance.

Among the latter, $v_{L}$ and $v_{L_{f}}$ are the least frequently employed in control loops. They are only briefly considered in [31] and used mainly to facilitate the implementation of proportional-integral-derivative (PID) regulators of the respective state variables. Therefore, $v_{L}$ and $v_{L_{f}}$ are not further considered herein.

With the remaining variables, that is, $i_{L}, i_{C}, v_{O}$, and $i_{G}$, it is possible to set-up 12 different cascaded controller structures. These can be further categorized as $A$ ) single-loop, $B$ ) doubleloop, and $C$ ) triple-loop. The classification is done without counting the feedforward of a variable as a loop.

\section{A. Single-loop control structures}

A single-loop control is implemented when only one variable is measured and regulated. In the case of the $L C L$ filter, the applicable variables are $i_{L}, v_{O}$, and $i_{G}$. Fig. 2 shows the single-loop structure, where $H_{S}$ refers to the applied regulator.

1) $i_{L}$ controller: commonly used in cost-sensitive industrial applications. It requires a single current sensor - a standard component of an inverter hardware - to provide overcurrent protection [5], [34]. Ref. [35] shows that $i_{L}$ controller has an inherent damping effect, which helps to neutralize the resonance introduced by the reactive $L C L$-filters' components.

In the past decades, various regulators were proposed for this type of structure, such as proportional (P) [36], 
proportional-integral (PI) [35], proportional-resonant (PR) [37]-[41], dead-beat (DB) [42], among which the PR regulator is prevalent. With this type of controller, adequate harmonic grid-current attenuation is not straightforward because the grid current is not directly controlled. Provisions are although available, like: $i)$ proper definition of the inverter current reference [43], ii) grid voltage feedforward [34], [44], or iii) capacitor-voltage feedforward [34], [45]. The principle behind the latter is that harmonic components of the grid current can be dampened as much as the inverter output voltage is able to replicate the grid voltage harmonic components in amplitude and phase.

2) $v_{O}$ controller: used in some applications of uninterruptible power supply (UPS) systems with $L C$ output filter [36], [46], [47], especially operating at low pulse-ratios (i.e., the ratio between the switching frequency and the grid fundamental frequency) [48], [49]. A typical example is given by airplane ground power supplies, with a fundamental frequency of up to $400 \mathrm{~Hz}$. Single-loop voltage control is applied to $L C L$-filter interfaced inverters too, as those employed for voltage-driven grid-supporting inverters in microgrids [15]. In this case, since $v_{O}$ is closed-loop controlled, an uninterrupted, high-quality local ac voltage can be guaranteed, which is beneficial for critical local loads [36], [46], [47]. Different regulators are compatible with this structure: P [36], [48], resonant (R) [47], [48], PR [48], [49], discrete Fourier transform (DFT) based ones [46] are possible solutions. Remarkably, this structure does not provide resonance damping or short-circuit protection, hence additional provisions are required to improve the system stability margin [48] and reliability.

3) $i_{G}$ controller: used mainly in grid-tied inverters. It shows merits in both harmonic rejection and power flow regulation [34], due to the direct control of the grid current. Harmonic regulation performance can be further enhanced by using resonant, multi-resonant, or repetitive regulators [34]. Still, passive or active damping methods are often necessary to improve stability. Passive methods consist in a proper design of the $L C L$-filter [50], possibly considering the insertion of damping elements [35], [51], which, however, may increase volume, cost, and power losses. Active methods consist in control provisions like 1) the addition of a further control loop involving, for example, the capacitor current [52], [53] or the output voltage [54], [55], as described in Sec. II-B, 2) the use of filter-based feedforward with notch [56], lead-lag [57], or all-pass filters [58]; and 3) the use of model-based reducedorder current control methods, implemented by splitting the filter capacitor [59] or by using weighted average current control [60]. Remarkably, model predictive control (MPC) algorithms, whose output acts directly on the PWM signals, show applicability to grid-tied inverter as well. Examples of application can be found in [61]-[64].

\section{B. Double-loop control structures}

When more than one variable is fed-back, the design of the controller gains more flexibility. In the case of power converters, multi-variable control is almost always set-up in a cascaded arrangement. A double-loop cascaded controller

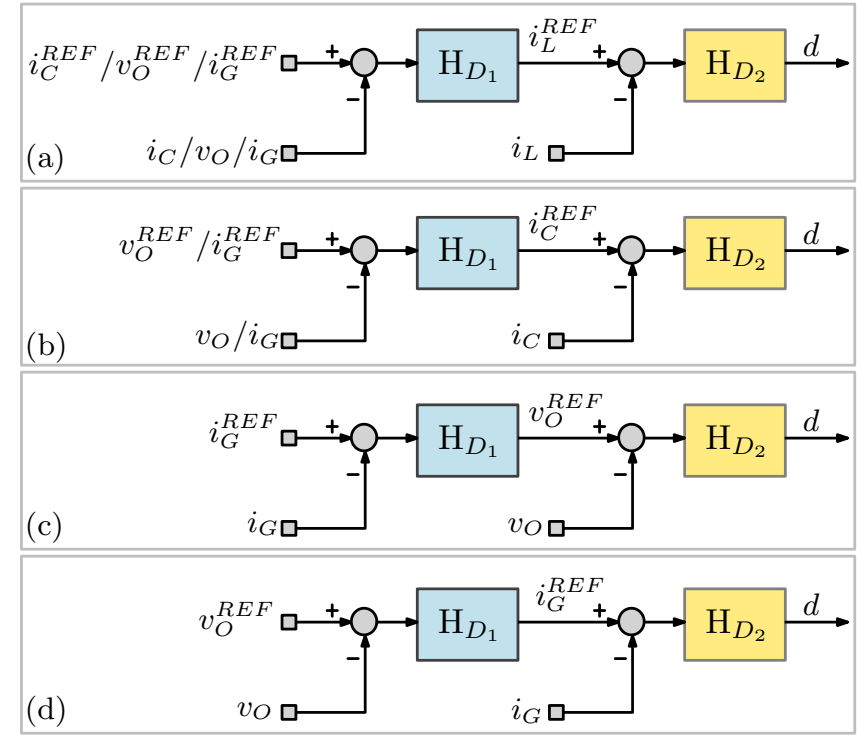

Fig. 3. Double-loop controller structures. $\mathrm{H}_{D 1}$ and $\mathrm{H}_{D 2}$ are the outer and inner loop regulators, respectively.

structure is established when two control variables are fedback, as shown in Fig. 3. In this case, seven controller structures can be set-up, indicated in the following by the respective controlled variables, from inner to outer loops: 1) $i_{L}-i_{C}, 2$ ) $i_{L}-v_{O}$, 3) $i_{L}-i_{G}$, 4) $\left.\left.i_{C}-v_{O}, 5\right) i_{C}-i_{G}, 6\right) v_{O}-i_{G}$ and 7) $i_{G}-v_{O}$.

1) $i_{L}-i_{C}$ controller: with the $i_{L}$ controller in Sec. II-A1, grid harmonics can freely flow through the filter capacitor $C_{O}$. The capacitor current $i_{C}$, being the derivative of the voltage $v_{O}$, carries information about the grid voltage harmonics, which is exploited in the $i_{L}-i_{C}$ double-loop controller for a better indirect control of the current $i_{G}$. The outer $i_{C}$ loop acts as a harmonic compensator (i.e., with reference set to zero for the harmonics), while the inner $i_{L}$ loop contributes to damp resonances [5], [65]. The signal $i_{C}$ can also be obtained by time-differentiating $v_{O}[5]$.

2) $i_{L}-v_{O}$ controller: widely used in uninterruptible power supply (UPS) systems with $L C$ filters [36], [66], it is also applicable to inverters with $L C L$ filters [67]-[69]. The controller structure is such that the inverter operates as a controlled voltage source. Various regulators (i.e., $H_{D_{2}}-H_{D_{1}}$ ) have been employed in this type of controller, most commonly: P-P [36], P-PI [49], P-PR [67], [68], [70], PI-PR [69], PR-PR [71], DBDB [66]. Among these, the P-PR is a very common solution.

3) $i_{L}-i_{G}$ controller: the double-loop control of $i_{L}$ and $i_{G}$ is an effective solution to simultaneously damp resonances and reduce grid current harmonics. Specifically, the grid-current $i_{G}$ is regulated by the outer loop that provides the reference for the inner, inductor current $i_{L}$ loop. So doing, the inverter is current-controlled. Different implementations of the regulators $H_{D_{2}}$ and $H_{D_{1}}$ can be found in the literature, such as the P-PI [72], [73], P-H ${ }^{\infty}$ [74], P-PR [31], [37], DB-PI [75], PR-R [76], hysteresis current control (HCC)-PR [77]. These regulators achieve a sufficiently fast response for the inner $i_{L}$ loop and a high-gain in the lower frequency region for the outer loop, beneficial for protection and reference tracking, respectively. 
4) $i_{C}-v_{O}$ controller: from Fig. 1 it is evident that the capacitor current $i_{C}$ can be derived directly from the output voltage $v_{O}$, meaning that these two variables are not independent. For this reason, in practice, it is not recommendable to control $i_{C}$ and $v_{O}$ concurrently [31]. This type of controller is only briefly presented in [49], where $v_{O}$ is the outer loop, controlled by a PR compensator, while $i_{C}$ is the inner loop, regulated by a simple $\mathrm{P}$ compensator. It is worth remarking that, in this controller structure, the inner $i_{C}$ loop is not a reference tracking loop, but simply adds to the voltage-loop output a signal that is proportional to $i_{C}$, which is just a convenient way to implement a derivative (D) control of $v_{O}$. As a result, the double-loop controller is functionally equivalent to a singleloop control of $v_{O}$ with a $\mathrm{PR}+\mathrm{D}$ regulator.

5) $i_{C}-i_{G}$ controller: as shown in [78], proportional feedback of the capacitor current $i_{C}$ is equivalent to a virtual inductance connected in parallel with the converter output capacitor $C_{O}$. Similarly to $i_{L}-i_{G}$ controllers, the inner capacitor current loop is exploited for system stabilization, while the outer loop is in charge of harmonic attenuation and power flow regulation. In some applications, it is possible to control the inner loop with a simple proportional regulator for the sole purpose of increasing the high-frequency loop gain, while steady-state errors in grid-current control are handled by the outer grid current loop [79]. The outer loop regulator varies from application to application; the literature reports the use of the simple PI control [79], [80], the PR [37], [40], [78], the PR + odd harmonic repetitive control (OHRC) [81] or the quasi-proportional-resonant fuzzy control [82].

6) $v_{O}-i_{G}$ controller and $i_{G}-v_{O}$ controller: in microgrid contexts, inverters are often expected to operate grid-tied as well as islanded. From this perspective, the $v_{O}-i_{G}$ controller allows the regulation of the exchanged power and the attenuation of the injected harmonics in grid-tied mode, and, by control switching, the islanded/autonomous operation with the inner $v_{O}$ loop; examples can be found in [83], [84]. To further enhance the system performance, an $\mathrm{H}^{\infty}$ synthesized regulator combined with a repetitive controller is adopted in both the loops in [83]. With this solution, the quality of the inverter local voltage and the injected grid current are improved simultaneously. However, the performance of $v_{O}-i_{G}$ controller can be significantly affected by the resonances induced by the $L C L$-filter, making it necessary to apply additional damping provisions. An interesting solution is proposed in [85], where the control loops are swapped, making $v_{O}$ the outer loop regulated by a virtual admittance to provide the reference for the inner $i_{G}$ loop, that employs a PR regulator. While addressing the resonance issue, this arrangement makes the realization of seamless mode transitions more complicated.

\section{Triple-loop control structures}

Triple-loop control is the latest controller structure proposed in the literature. It is more complex to analyze and implement than double- or single-loop solutions, because each loop bandwidth is limited by the inner loop response delay. Specifically, with three cascaded loops, it is difficult to achieve wide bandwidths on the outer one.

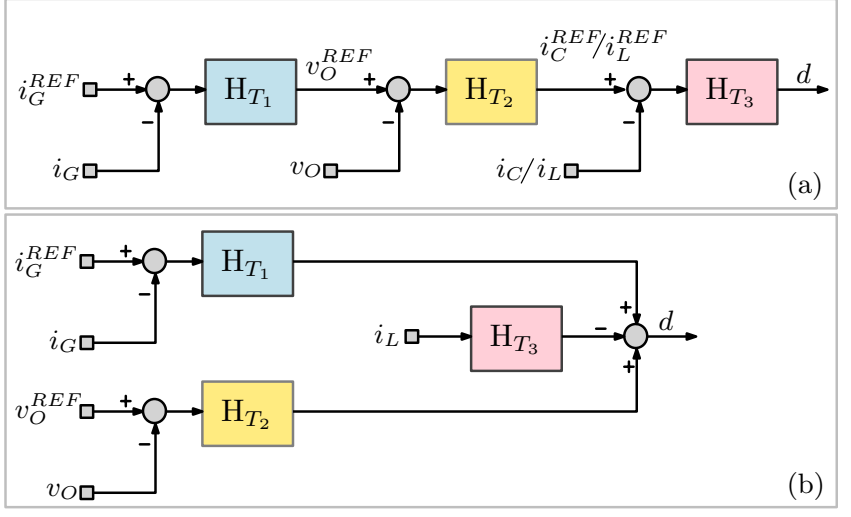

Fig. 4. Triple-loop controller structures. (a) Cascaded pattern, (b) parallel pattern. $\mathrm{H}_{T x}, x=1,2,3$, are the regulators.

Although, in principle, there might be other structures, only two variants are discussed in the literature, namely, the $i_{L^{-}} v_{O^{-}}$ $i_{G}$, and the $i_{C}-v_{O}-i_{G}$, which are described in the following.

1) $i_{L}-v_{O}-i_{G}$ controller: it is similar to the $v_{O}-i_{G}$ doubleloop controller, but has an inherent damping effect, thanks to the insertion of the innermost $i_{L}$ loop. The controller can be configured in two different ways, namely, $i) i_{L}-v_{O^{-}}$ $i_{G}$ controller, where $i_{L}, v_{O}$, and $i_{G}$ loops are connected in cascade as displayed in Fig. 4(a) [86]-[90]; ii) $i_{L}+v_{O}+i_{G}$ controller, where the three loops are connected in parallel as displayed in Fig. 4(b) [91]-[93]. As far as the $i_{L}-v_{O}-i_{G}$ controller is concerned, different regulators can be used: (from inner to outer loops), DB-DB-PI [86], PR-PR-PR [88], DBPID-repetitive filter [87], hysteresis control-PI-P [90], P-PRPR [89]. For $i_{L}+v_{O}+i_{G}$ controller, instead, $i_{G}$ is controlled by a PR regulator, $i_{L}$ is controlled by a $\mathrm{P}$ regulator, while $v_{O}$ can be controlled either by an R [91], [92] or PR regulator [93].

2) $i_{C}-v_{O}-i_{G}$ controller: instead of controlling $i_{L}$, it is possible to control $i_{C}$ in the innermost loop, as in [94], [95]. Only one type of regulator combination is found, which is organized in a cascaded way: innermost $i_{C}$ loop, intermediate $v_{O}$ loop, and outer $i_{G}$ loop, with P, PI, and PI regulators, respectively. Similar to the double-loop $i_{C}-v_{O}$ controller, the $i_{C}$ loop in this controller supports the intermediate $v_{O}$ loop, instead of acting as a tracking loop. Because of that, it is functionally equivalent to a double-loop $v_{O}-i_{G}$ controller with PID-PI regulators.

Compared with the single- and double-loop controllers, a triple-loop controller provides the highest control flexibility, which can be beneficial for a safer and higher performance operation of grid-tied inverters. However, measures must be taken in the triple-loop controllers to reduce control delays and, thus, to maximize performance. To this purpose, [42], [96], [97] propose the use of predictive control, while [78], [98], [99] suggest means to minimize the sampling delays.

A panoramic view of the existing controllers for grid-tied inverters is provided in Tab. I.

\section{Control Functionalities}

With the development of microgrids, more and more control functionalities have been proposed and requirements identi- 
TABLE I

CLASSIFICATION OF CONTROLLERS FOR GRID-TIED INVERTERS

\begin{tabular}{|c|c|c|c|c|c|}
\hline Pattern & Loop & Inverter type & $\begin{array}{c}\text { Structure } \\
\text { (inner-outer) }\end{array}$ & $\begin{array}{c}\text { Regulator } \\
\text { (inner-outer) }\end{array}$ & Reference \\
\hline \multirow{41}{*}{ cascaded } & \multirow{11}{*}{ single } & \multirow{7}{*}{$\begin{array}{l}\text { current- } \\
\text { controlled }\end{array}$} & \multirow[t]{5}{*}{ (2) } & proportional $(\mathrm{P})$ & {$[36]$} \\
\hline & & & & proportional-integral $(\mathrm{PI})$ & {$[34],[35],[41]$} \\
\hline & & & & $\begin{array}{l}\text { robust inverter current feedback } \\
\text { resonance supression (ICFRS) + PI }\end{array}$ & [100] \\
\hline & & & & proportional-resonant (PR) & [37]-[41] \\
\hline & & & & deadbeat $(\mathrm{DB})$ & {$[42]$} \\
\hline & & & \multirow{2}{*}{$i_{G}$} & PR + high pass filter(HPF) & [101] \\
\hline & & & & $\begin{array}{l}\text { grid current feedback resonance supression (GCFRS) } \\
\text { + quasi-proportional resonant (QPR) regulator }\end{array}$ & [102] \\
\hline & & \multirow{4}{*}{$\begin{array}{l}\text { voltage- } \\
\text { controlled }\end{array}$} & \multirow{4}{*}{$v_{O}$} & $\mathrm{P}$ & [36], [48] \\
\hline & & & & resonant $(\mathrm{R})$ & {$[47],[48]$} \\
\hline & & & & PR & [48], [49] \\
\hline & & & & discrete Fourier transform (DFT) & [46] \\
\hline & \multirow{24}{*}{ double } & \multirow{15}{*}{$\begin{array}{l}\text { current- } \\
\text { controlled }\end{array}$} & \multirow[b]{2}{*}{$i_{L}-i_{C}$} & PR - P & {$[5]$} \\
\hline & & & & $(\mathrm{D}-\Sigma)-\mathrm{P}$ & {$[65]$} \\
\hline & & & \multirow{6}{*}{$i_{L}-i_{G}$} & P - PI & [72], [73] \\
\hline & & & & $\mathrm{P}-\mathrm{H}^{\infty}$ & [74] \\
\hline & & & & $\mathrm{P}-\mathrm{PR}$ & [31], [37] \\
\hline & & & & DB - PI & {$[75]$} \\
\hline & & & & PR - R & [76] \\
\hline & & & & hysteresis current control (HCC) - PR & [77] \\
\hline & & & \multirow{4}{*}{$i_{C}-i_{G}$} & P - PI & {$[79],[80],[103]$} \\
\hline & & & & $\mathrm{P}-\mathrm{PR}$ & {$[31],[37],[40],[78],[103]$} \\
\hline & & & & P - (PR+ odd harmonic repetitive control (OHRC)) & {$[81]$} \\
\hline & & & & P - QPR fuzzy control & [82] \\
\hline & & & \multirow{3}{*}{$v_{O}-i_{G}$} & $\mathrm{D}-\mathrm{PR}$ & [84] \\
\hline & & & & $\mathrm{H}^{\infty}$ repetitive - PR & [83] \\
\hline & & & & $\mathrm{H}^{\infty}$ repetitive $-\mathrm{H}^{\infty}$ repetitive & [83] \\
\hline & & \multirow{9}{*}{$\begin{array}{l}\text { voltage- } \\
\text { controlled }\end{array}$} & \multirow{6}{*}{$i_{L}-v_{O}$} & $\mathrm{P}-\mathrm{P}$ & {$[36],[104]$} \\
\hline & & & & $\mathrm{P}-\mathrm{PI}$ & {$[49]$} \\
\hline & & & & $\mathrm{P}-\mathrm{PR}$ & {$[67],[68],[70]$} \\
\hline & & & & PI - PR & {$[69]$} \\
\hline & & & & PR - PR & [71] \\
\hline & & & & DB - DB & [66] \\
\hline & & & \multirow{2}{*}{$i_{C}-v_{O}$} & P - PI & [49] \\
\hline & & & & $\mathrm{P}-\mathrm{PR}$ & [31] \\
\hline & & & $i_{G}-v_{O}$ & $(\mathrm{PR}+\mathrm{D})$ - virtual admittance & [85] \\
\hline & \multirow{6}{*}{ triple } & \multirow{6}{*}{$\begin{array}{l}\text { current- } \\
\text { controlled }\end{array}$} & \multirow{5}{*}{$i_{L}-v_{O}-i_{G}$} & $\mathrm{P}-\mathrm{PR}-\mathrm{PR}$ & [89] \\
\hline & & & & PR - PR - PR & [88] \\
\hline & & & & DB - DB - PI & [86] \\
\hline & & & & DB - PID - repetitive & [87] \\
\hline & & & & HCC - PI - P & {$[90]$} \\
\hline & & & $i_{C}-v_{O}-i_{G}$ & P - PI - PI & [94], [95] \\
\hline \multirow{2}{*}{ parallel } & \multirow{2}{*}{3 branches } & & \multirow{2}{*}{$i_{L}+v_{O}+i_{G}$} & $P+R+P R$ & {$[91],[92]$} \\
\hline & & & & $\mathrm{P}+\mathrm{PR}+\mathrm{PR}$ & [93] \\
\hline
\end{tabular}

fied for grid-tied inverters, which made standardization an imperative. Different countries (e.g., USA, Germany) and international organizations [e.g., Institute of Electrical and Electronics Engineers (IEEE), the International Electrotechnical Commission (IET)] have participated in this process and released important standards [29]. Standards like IEEE 15472018 [3], IEC 61727 [105], IEEE 2030.7 [106], and IEEE 929 [107], together with national standards like RULE 21 [108] and VDE-AR-4105 [109] specifically refer to low-voltage microgrids and represent the basis of the following discussion.

\section{A. Functionalities overview}

Microgrids are expected to present specific features concerning stability, flexibility, scalability, and grid supporting capabilities [16], [110]-[112]. In particular, microgrids should i) present adequate stability margins in both steady-state and transient conditions; ii) be able to automatically react to faults to allow prompt restoration of normal operating conditions for loads and sources; iii) extend operation by transitioning to the islanded mode; $i v$ ) offer the possibility to seamlessly add, or remove, loads and sources; v) provide services like grid-support, dispatchability, data-logging, remote diagnostic. Grid-tied inverters enable such advanced functionalities.

Standards like [3], [105], [107]-[109], [113] define a set of versatile functionalities to be implemented by grid-tied inverters. Others have been identified and proposed in the literature, like [18], [111], [112], [114]-[116]. Altogether, the set of functionalities can be categorized by referring to four circumstances of operation, denoted in Fig. 5 as grid-tied (G), islanded or autonomous (I/A), transition from $\mathrm{G}$ to I-or-A $(\rightarrow \mathrm{I} / \mathrm{A})$, and transition from $A$ to $\mathrm{G}$-or-I $(\rightarrow \mathrm{G} / \mathrm{I})$. In addition to that, it is important to distinguish normal and abnormal operating conditions.

1) Grid-tied mode $(G)$ : active and reactive power support to the upstream grid (i.e., grid-support), and harmonic current 


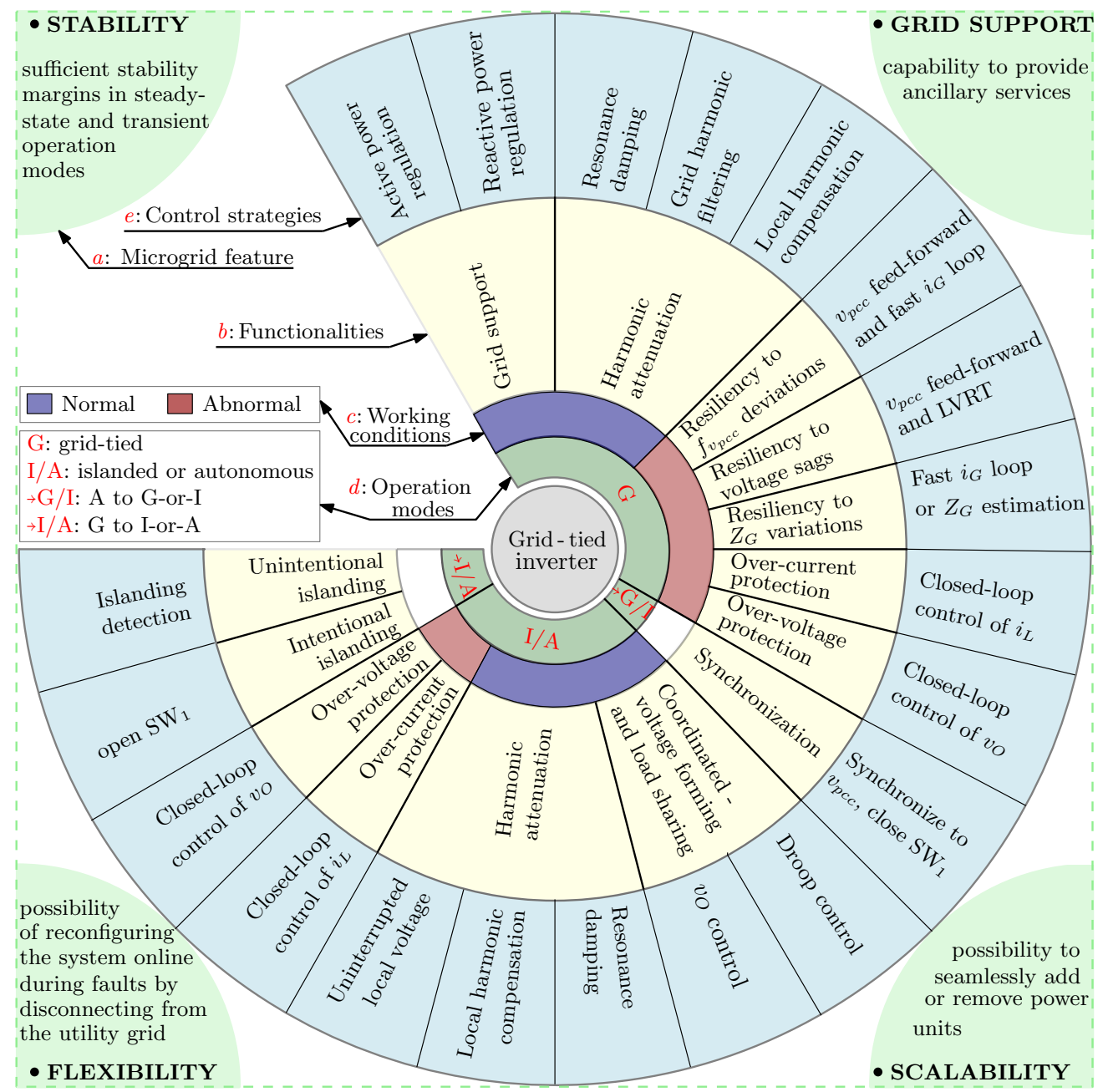

Fig. 5. Overview of microgrid features. The corners illustrate the four fundamental features of microgrids (a). From the perspective of a grid-tied inverter (at the center), the required functionalities $(b)$ are listed with respect to different working conditions $(c)$ and operation modes $(d)$. The associated control techniques $(e)$ are displayed for each functionality.

attenuation [117] are the most important functionalities of a grid-tied inverter under normal conditions. Distributed inverters can respond to power commands [29], [114], [118], [119] issued by local microgrid controllers or other external entities (e.g., DSO) [3], [106]. Instead, grid-support is automatically provided by means of droop control [12], [19], [120]-[122]. Droop control performs suitably with predominantly inductive or resistive grids, however, in the general case of mixed interconnection impedances, control performance can significantly degrade [123]. To cope with this issue, virtual impedance implementation has been proposed, which minimizes the uncertainty on the impedance seen by the inverters and decouples active and reactive power regulation [71], [124], [125]. Droop control may also be modified in order to allow output power flow regulation [126]. Harmonic attenuation functionalities are realized by damping the $L C L$-filter reactive behavior [127]-[130], by rejecting the grid-side harmonics [16], [111], [115], [117], [131]-[133], and by compensating the pollution possibly caused by local distorting loads [134].

As far as abnormal conditions are concerned, perturbations like frequency variations [29], [115], voltage sags [135]-[138], and impedance variations [139]-[141] are commonly encountered, especially in weak grids. To minimize the impact of grid voltage sags on the power system, low-voltage ride through capabilities are often requested [137], [138]. In general, system resiliency to grid voltage disturbances, in frequency or in amplitude, can be improved by feed-forwarding the grid voltage [142], [143] to the voltage loop or directly to the modulator. However, the effectiveness of grid voltage feed-forward can lessen when the grid-impedance increases, in which case it actually becomes a feedback loop. Apart from that, a higher than expected grid impedance tends to narrow the bandwidth of grid current controller and lead to instability. In order to enhance resiliency against grid impedance variations, possible solutions are i) maximize the control loop bandwidths by design [86], ii) use adaptive control techniques [144] based on grid-impedance estimation, or iii) adopt on-line auto-tuning techniques that adjust the control loop gains [7]. Finally, because overcurrent and overvoltage conditions can trigger faults and damage the inverter, specific hardware and software protections are mandatory for any grid-tied inverter [1], [145]. 
2) Islanded or autonomous mode (I/A): in these modes, the definition of the grid voltage is demanded directly to the inverters, which requires coordinated voltage forming and load sharing functionalities. In autonomous mode with a single inverter, suitable voltage control ensuring low output impedance is crucial to ensure good voltage quality for local loads and stability. The matter becomes more complex in islanded operation, where an isolated group of interconnected inverters and loads should operate stably and harmoniously. Different configurations of distributed sources are possible [15], [146] to allow the definition of the islanded system voltage and frequency. These configurations rely on inverters behaving as voltage sources with low output impedance or current sources with high output impedance, and other higher level means of coordination. Droop control is the most renown solution, sitting at the primary control layer in Fig. 1 [9], which makes use of voltage-controlled inverters. Another known alternative is the master/slave architecture [147] which employs a voltagecontrolled inverter as master unit that defines the grid voltage and frequency, and multiple current-controlled converters as slave units, behaving as grid feeding converters. Remarkably, in I/A modes the resulting system may be weaker than in grid-tied operation, which may require dedicated studies to ensure the stability of all interacting zero-level controllers. These system-level studies are typically performed by referring to the inverters output impedances [8], [148], [149].

3) Transition from grid-tied to islanded / autonomous mode $(\rightarrow I / A)$ : the transition to the islanded or the autonomous modes can be performed in either an unintentional or intentional way. The former type of transition is defined as a sudden disconnection of an electrical subsystem from the utility grid, without any prior notification to the subsystem undergoing the transition. Intentional islanding refers to the opposite situation, where the transition to the islanded operation is initiated by the subsystem itself [150]. Unintentional and intentional transitions are herein represented with the opening of $\mathrm{SW}_{2}$ and $\mathrm{SW}_{1}$, respectively, in Fig. 1. At the occurrence of unintentional islanding, if no provisions are taken, the grid-tied inverter may experience severe current and voltage transients or even incur into instability [63] while still energizing the islanded network. For safety reasons, the implementation of some islandingdetection functionality is mandatory by many national grid standards.

4) Transition from autonomous to grid-tied / islanded mode $(\rightarrow G / I)$ : for the interconnection of two systems that initially operate independently, synchronization is necessary to prevent undesirable transients. This is the case, for example, of the closure of $\mathrm{SW}_{1}$ for the connection of an inverter operating autonomously with a functional islanded system (if $\mathrm{SW}_{2}$ is open) or with the grid (if $\mathrm{SW}_{2}$ is closed). Synchronization is normally realized by means of a phase-locked loop (PLL) and, for voltage controlled converters, it may be assisted by soft-start techniques, like virtual output impedance control [9]. Solutions are proposed in the literature to limit transients and perform smooth transitions [63]. These can be divided into three categories with respect to the used controller: $i$ ) voltagecontrol based approach [151], [152], ii) current-control based approach [94], [153], and iii) hybrid approach [154].

\section{B. Functionalities and control-strategies relations}

In this section, the control structures discussed in Sec. II are related to the functionalities outlined in Sec. III-A. The discussion eventually brings to the table in Fig. 6, which shows the functionalities that can be practically implemented with the different control structures, considering normal and abnormal operating conditions. For better readability, only the control structures of cascaded type are presented.

1) Normal operation: power flow control, harmonic attenuation, and smooth mode transitions are required during normal operation. Output power control can be directly achieved with structures controlling the inverter current $i_{L}$ or the grid current $i_{G}$; in this case, active or reactive power injection is determined by combining current references that are inphase, for active power, and in-quadrature, for reactive power, with respect to the measured output voltage. Differently, power control requires additional higher-level regulators in structures controlling the output voltage $v_{O}$, as indicated in Fig. 6. A typical solution is the droop control plus a power regulator [126]. Droop control also allows an automatic coordination of active and reactive power contributions by grid-tied inverters (see Fig. 4 in [15]). In voltage controlled inverters, the frequency and amplitude of their output voltage reference is slowly adjusted by an outer droop controller on the basis of the measured active and reactive output powers. In current controlled inverters, instead, their inductor current reference or grid current reference is slowly adjusted by an outer droop controller on the basis of the measured output voltage amplitude and frequency. In both cases, good reference tracking in steady-state can be achieved by a good control of the output voltage $v_{O}$, for the voltage controlled case, or output current $i_{L}$, or $i_{G}$, for the current control case. In this last case, structures allowing $i_{G}$ control are particularly effective in reducing harmonic circulation and implementing virtual output impedances. Smoothness of mode transitions requires that both the local voltage $v_{O}$ and the injected grid current $i_{G}$ can be kept well controlled to avoid discontinuities during the transitions among grid-tied, islanded, and autonomous modes. This benefits from $i$ ) accurate output voltage control and synchronization while not connected, ii) fast control of grid current $i_{G}$ to limit transients at the connection. Accordingly, controllers that integrate both grid current and output voltage loops are preferable for the implementation of effective transition procedures (see, e.g., [90], [150]).

2) Abnormal condition: equivalent circuits of voltagecontrolled inverter (VCI), indirect current-controlled inverter (ICCI), and direct current-controlled inverter (DCCI) operating in grid-tied mode are illustrated in Fig. 7. For simplicity, the inverters are assumed to be controlled as ideal voltage or current sources. According to Fig. 7, the perturbation of grid current $\Delta i_{G}$ induced by variations of grid voltage, $\Delta v_{G}$, and grid impedance, $\Delta Z_{g}$, can be written for the case of VCI, ICCI, and DCCI as:

$$
\Delta i_{G}=-\frac{\Delta v_{G}}{Z_{L_{F}}+Z_{g}}+\frac{v_{G} \cdot \Delta Z_{g}}{\left(Z_{L_{F}}+Z_{g}\right)^{2}}
$$




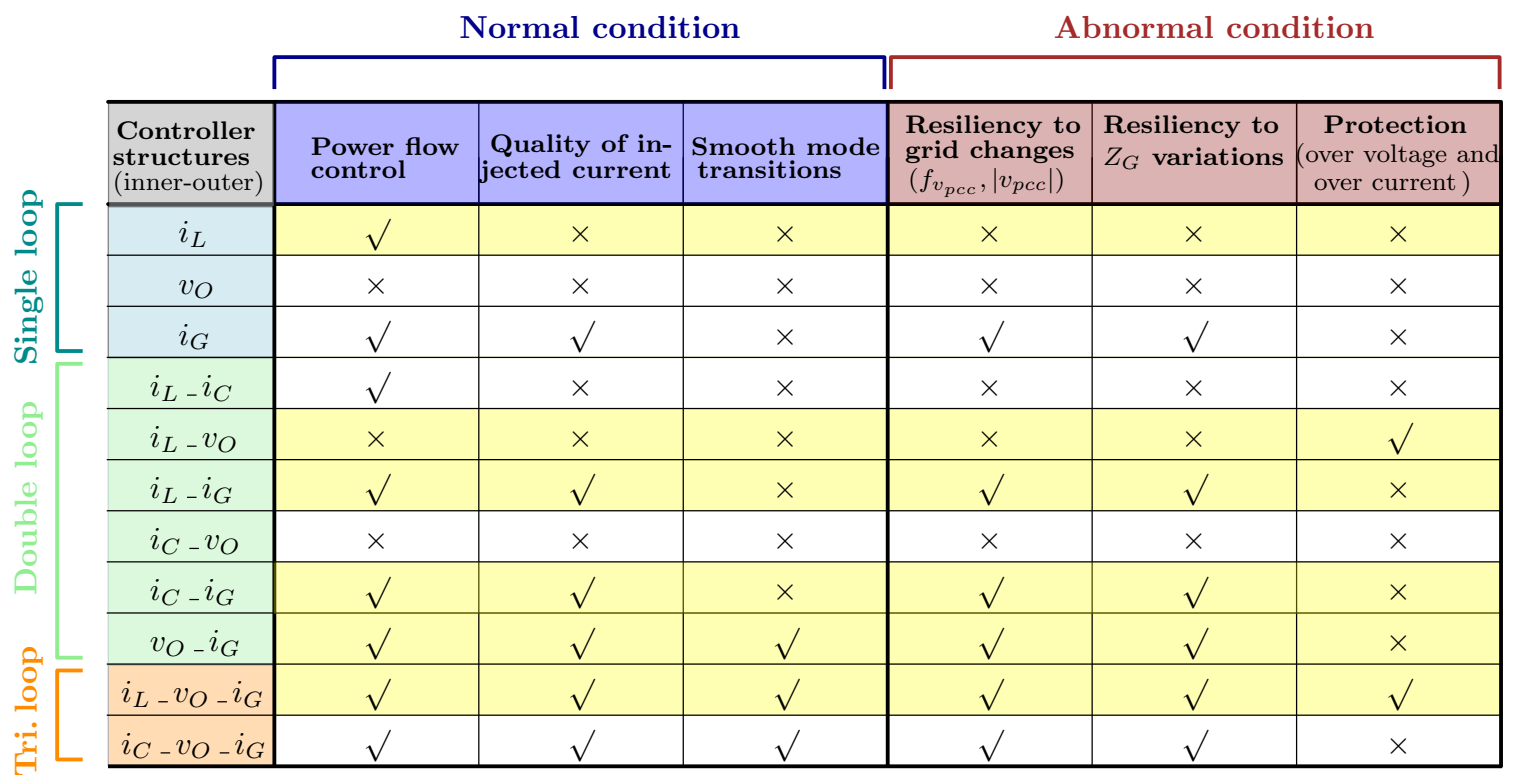

Fig. 6. Controller performance $(\sqrt{ }$ : practical implementation, $\times$ : implementation not straightforward). The most representative controller structures are highlighted in yellow.

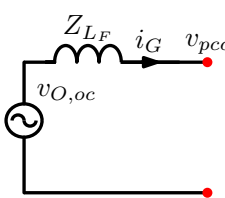

(a)

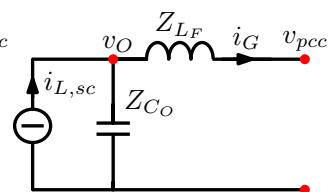

(b)

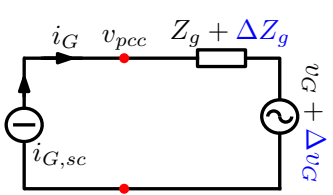

(c)
Fig. 7. Inverters equivalent circuits: (a) voltage controlled inverter; (b) indirect current controlled inverter; (c) direct current controlled inverter.

$$
\begin{gathered}
\Delta i_{G}=-\frac{\Delta v_{G}}{Z_{L_{F}}+Z_{g}+Z_{C_{O}}}+\frac{v_{G} \cdot \Delta Z_{g}}{\left(Z_{L_{F}}+Z_{g}+Z_{C_{O}}\right)^{2}} \\
\Delta i_{G}=0,
\end{gathered}
$$

respectively. Equations (1)-(3) show that larger grid current perturbations appear in VCI than in ICCI (the denominator is larger in the latter case) for given voltage or impedance variations. At the same time, DCCI virtually offers maximum resiliency to both the grid perturbations. In this case, largebandwidth control of the grid current $i_{G}$, which implies higher inverter output impedance, is more suitable for improving system resiliency to grid perturbations.

Overcurrent and overvoltage protections can be easily realized when closed-loop control of both the inductor current $i_{L}$ and output voltage $v_{O}$ are implemented. To this purpose, fast sampling helps to rapidly identify the overcurrent or overvoltage conditions and a large control bandwidth guarantees voltage and current within reasonable levels.

\section{CASE STUdY}

On the basis of the presented review, the most representative controller structures, highlighted in yellow in Fig. 6, are evaluated experimentally in this section. The following regulators are considered: i) $i_{L}$ control, the most common solution for implementing basic current-controlled inverters, like the widely used PV inverters for residential installations, ii) $i_{C}-i_{G}$ control, an evolution of the previous controller, typically used to achieve better grid-current quality, iii) $i_{L}-v_{O}$ control, the basic solution for voltage-controlled inverters, like those used in combination with droop control in low-voltage microgrids, $i v) i_{L}-i_{G}$ control, a very common variant of the $i_{C}-i_{G}$ case, v) $v_{O^{-}} i_{G}$, the basic solution to implement systems able to operate both grid-tied and autonomously, because it has local-voltage and grid-current control capabilities and, finally, vi) $i_{L}-v_{O}-i_{G}$ control, the solution where all the filter variables are closed-loop controlled.

For a fair comparison, the same grid-tied inverter set-up as defined in Fig. 1 is used in all the tests, whose parameters are reported in Tab. II. Besides, the different controller structures use the same type of regulator for the same controlled variable: a) deadbeat regulators are employed in $i_{L}$ and $v_{O}$ loops to ensure maximum bandwidth; $b$ ) the $i_{G}$ loop is designed to achieve the maximum allowable bandwidth compatible with a minimum phase margin of $60^{\circ} ; \mathrm{c}$ ) none of the possible narrow bandwidth (i.e., steady-state) harmonic attenuation provisions (e.g., resonant regulators) is used. Tab. III summarizes the characteristics of the six controllers implemented. For clarity, the implemented regulator algorithms for variables $i_{L}, v_{O}$, and $i_{G}$ are, respectively:

$$
\begin{aligned}
& d(k)=\frac{L f_{s w}}{V_{D C}} \cdot\left[i_{L}^{R E F}(k)-i_{L}(k)\right]+\frac{v_{O}(k)}{2 V_{D C}}+\frac{1}{2}, \\
& i_{L}^{R E F}(n)=C_{O} f_{s w} \cdot\left[v_{O}^{R E F}(n)-v_{O}(n)\right]+i_{O}(n), \\
& v_{O}^{R E F}(n)=\mathrm{H}_{i_{G}} \cdot\left[i_{G}^{R E F}(n)-i_{G}(n)\right],
\end{aligned}
$$

where $\mathrm{H}_{i_{G}}(z)=K_{p}+K_{i} \cdot z /(z-1)$ is the grid-current digital PI regulator. Further details can be found in [86], [150] and in 
TABLE II

GRID-TIED INVERTER PARAMETERS (SCHEME IN FIG. 1)

\begin{tabular}{llrc}
\hline Parameter & Symbol & \multicolumn{2}{c}{ Value } \\
\hline Nominal dc link voltage & $V_{D C}$ & 450 & $\mathrm{~V}$ \\
Switching frequency & $f_{s w}$ & 20 & $\mathrm{kHz}$ \\
Sampling frequency & $f_{s}$ & 40 & $\mathrm{kHz}$ \\
Filter inductance & $L$ & 1.40 & $\mathrm{mH}$ \\
Inductor equivalent resistance & $E S R_{L}$ & 60 & $\mathrm{~m} \Omega$ \\
Output capacitance & $C_{O}$ & 30 & $\mu \mathrm{F}$ \\
Line inductance & $L_{F}$ & 0.55 & $\mathrm{mH}$ \\
Inductor equivalent resistance & $E S R_{L_{F}}$ & 75 & $\mathrm{~m} \Omega$ \\
Nominal power & $S_{O}$ & 3 & $\mathrm{kVA}$ \\
Nominal voltage & $V_{N}$ & 230 & $\mathrm{~V}$ \\
Nominal current & $I_{N}$ & 13 & $\mathrm{~A}$ \\
\hline
\end{tabular}

[42], [155], [156], with particular reference to the parametric sensitivities of all controllers.

The controls are prototyped in a National Instruments cRIO controller [157] that embeds a Xilinx Zynq 7020 systemon-a-chip. To compare the different organizations fairly, the dc link is considered ideal, connected to a laboratory dc power supply to feed the inverter. This makes the grid-side performance of the different controllers independent from the dc link dynamics, which might have a different impact on each of them otherwise. In the practical case, different solutions can be applied to achieve the same de-coupling effect, that are widely documented in the literature [158], [159]. For the controller (4), in particular, the standard practice is to sample $V_{D C}$ at every control iteration, so that the state trajectory of $i_{L}$ can be always computed with the correct dc link voltage value. It is shown in the literature how this simple provision can achieve a practically ideal de-coupling of the ac inverter side performance from the dc link dynamics.

\section{A. Steady-state performance}

Three test conditions are considered: $a$ ) ideal grid, considered as benchmark, where a pure sinusoidal grid voltage is supplied by an ac laboratory power supply; $b$ ) distorted grid, where multiple low-order harmonics (i.e., $5 \%$ of $3 \mathrm{rd}$, 5th, and 7th harmonic) are added to the grid voltage; $c$ ) distorted grid with local non-linear load (NLL), where a non-linear load is also added in parallel with the filter capacitor $C_{O}$.

The waveforms from the different tests are shown in Fig. 8, while THD measures are reported in Tab. IV and Tab. V. On the basis of the obtained results, the following comments can be made.

- The $i_{L}-v_{O}$ and the $i_{L}-v_{O}-i_{G}$ controllers show better harmonic attenuation for local voltage $v_{O}$ and injected grid current $i_{G}$, respectively, as can be seen in Fig. 8 and confirmed by the THD values in Tab. IV and Tab. V. Without any specific harmonic attenuation provision, $\mathrm{THD}_{v_{O}}$ equals $6.29 \%$ with the $i_{L}-v_{O}$ controller, while $\mathrm{THD}_{i_{G}}$ equals $2.58 \%$ with the $i_{L}-v_{O}-i_{G}$ controller, even under the distorted test conditions of case $c$ ).

- Comparing Fig. 8.5(c) and Fig. 8.6(c), the importance of the $i_{L}$ loop in damping resonances emerges. Indeed, the harmonic attenuation improves: $\mathrm{THD}_{i_{G}}$ reduces from $4.68 \%$, in the case $v_{O^{-}} i_{G}$, to $2.58 \%$, in the case $i_{L^{-}} v_{O^{-}}$ $i_{G}$.

- Controllers $i_{C}-i_{G}, i_{L}-i_{G}, v_{O}-i_{G}$ and $i_{L}-v_{O}-i_{G}$ show a higher quality of the injected power than the other cases where grid current $i_{G}$ is not controlled (i.e., $i_{L}$ and $i_{L^{-}}$ $\left.v_{O}\right)$. This is consistent with the discussion in Sec. III-A and agrees with the analysis in Fig. 6.

- Test condition $b$ ) and $c$ ) differ by the presence of the NLL, absorbing a distorted current. Notably, Tab. IV with Tab. V show increased values of $\mathrm{THD}_{i_{G}}$ in the cases $i_{L}$, $i_{C}-i_{G}$ and $i_{L}-i_{G}$, whilst marginal changes for the three cases where output voltage $v_{O}$ is directly controlled (i.e., $i_{L}-v_{O}, v_{O}-i_{G}$, and $\left.i_{L}-v_{O}-i_{G}\right)$. This shows experimentally the effectiveness of output voltage control in compensating harmonics generated by local loads.

- Tab. V and Tab. IV show that $v_{O}-i_{G}$ and $i_{L}-v_{O}-i_{G}$ controls provide better overall performance. Even without any specific harmonic attenuation provisions and under severely distorted operating conditions, grid current of good quality can be achieved, easily complying with gridinterface standards (i.e., $\mathrm{THD}_{i_{G}}<5 \%$ ).

\section{B. Dynamic performance}

As explained in Sec. III-B1, output power control can be directly achieved with structures controlling the inverter current $i_{L}$ or the grid current $i_{G}$, while it requires additional higherlevel regulators in structures controlling the output voltage $v_{O}$, as indicated in Fig. 6. The response in these two cases are reported in Fig. 9, considering a step change of the active power reference from 0 to $700 \mathrm{~W}$. The transient is prompt in the case of a grid-tied inverter with $i_{C}-i_{G}$ control, while it lasts several grid cycles in the case of a grid-tied inverter with $i_{L}-v_{O}$ control. Equivalent conclusions hold with the other structures controlling the output current or voltage. Regardless of the specific control structure, power regulation may be performed precisely and with transients in the order of $100 \mathrm{~ms}$, which is enough to comply with standards like IEEE 1547-2018 [3].

\section{Stability considerations}

The stability of any interconnection of multiple systems that are stable when considered singularly can be studied by referring to their output impedances and applying methods like [8], [148], [149]. The Middlebrook criterion [160] gives a sufficient condition for the stability of an inverter with output impedance $Z_{\text {out }}$ connected to a grid of impedance $Z_{g}$, namely, $\left|Z_{g}\right| /\left|Z_{\text {out }}\right|<1$. Considering the implemented control structures, Fig. 10 shows the measured impedance magnitudes. Qualitatively, among the current controlled structures, the $i_{L}$ control shows the lowest impedance around resonance, while double and triple loop solutions allow better conditions referring to the impedance ratio $Z_{g} / Z_{\text {out }}$. An exact assessment can be performed by Nyquist plot analysis of the impedance ratio. Five conditions are reported in Fig. 11 to show the potentially unstable interactions, relevant to the zero-level control (see Fig. 1), when multiple converters are interconnected. In particular: a) is the case of a grid-feeding [15] inverter 

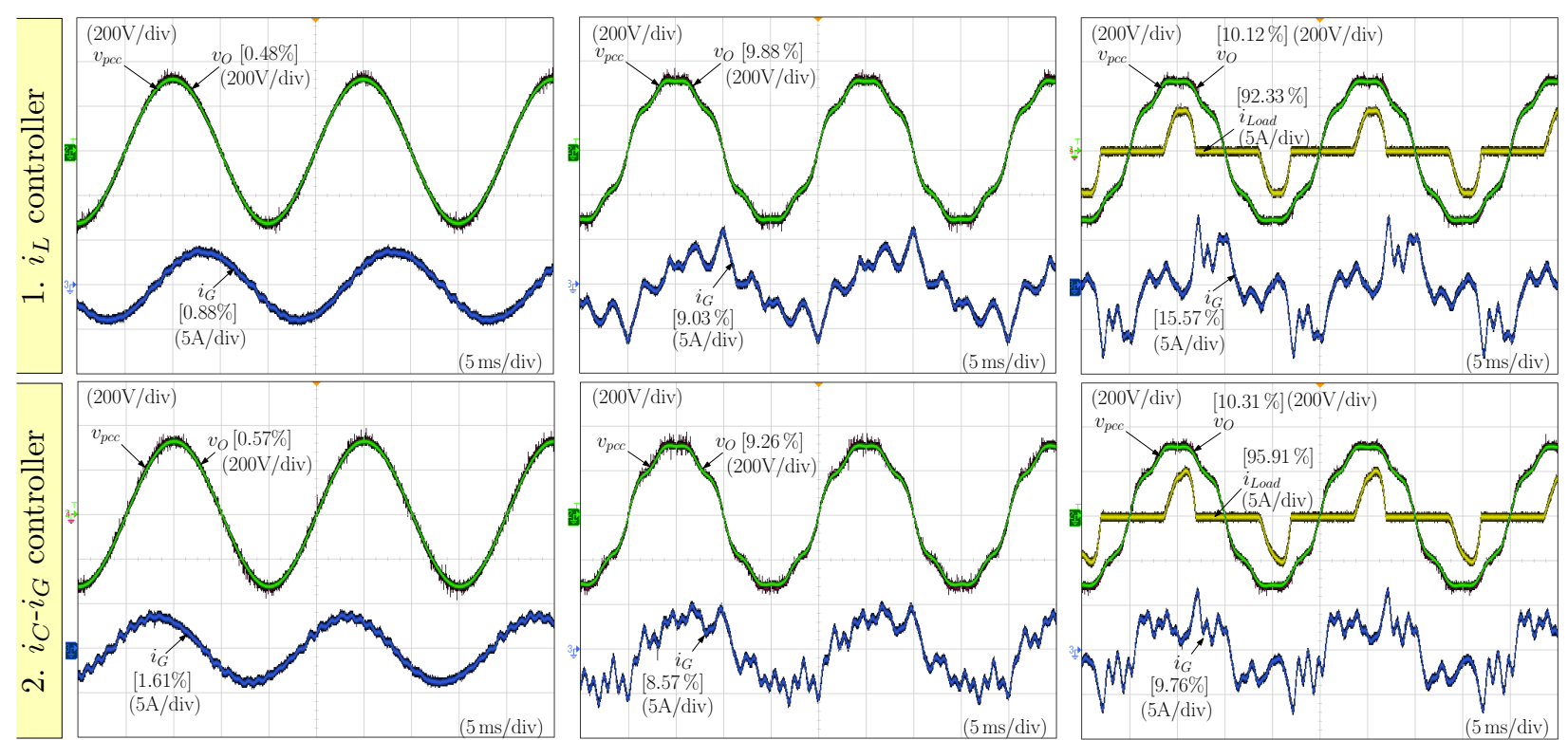

(200V/div) [10.31\%](200V/div)
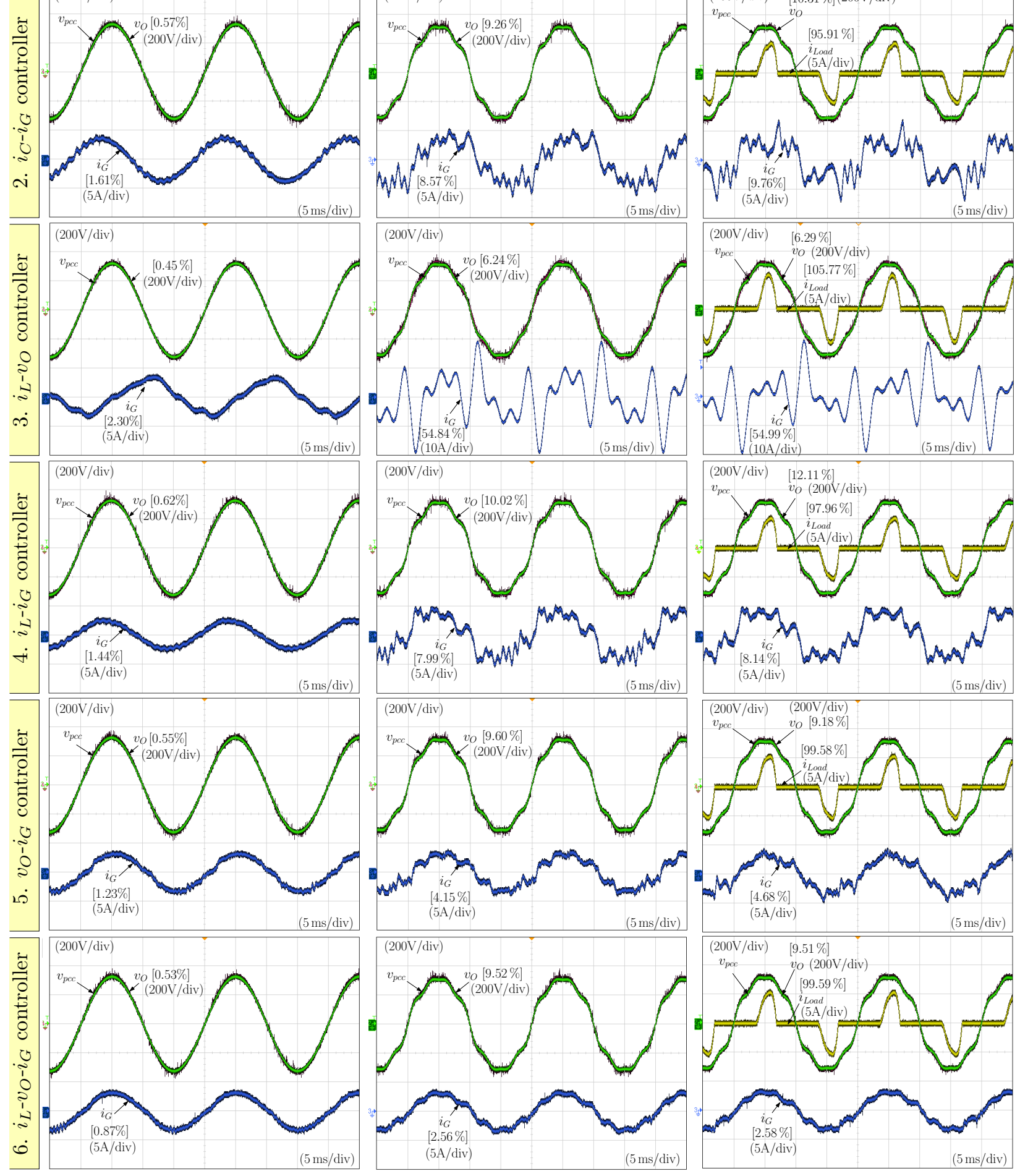

test condition $a$ )

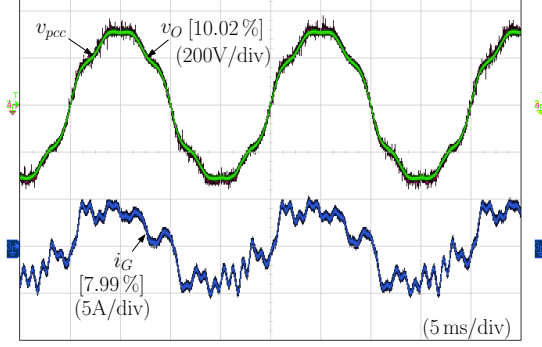

$\begin{array}{ll}(200 \mathrm{~V} / \mathrm{div}) & {[12.11 \%]} \\ v_{0}(200 \mathrm{~V} / \mathrm{div}) & \end{array}$
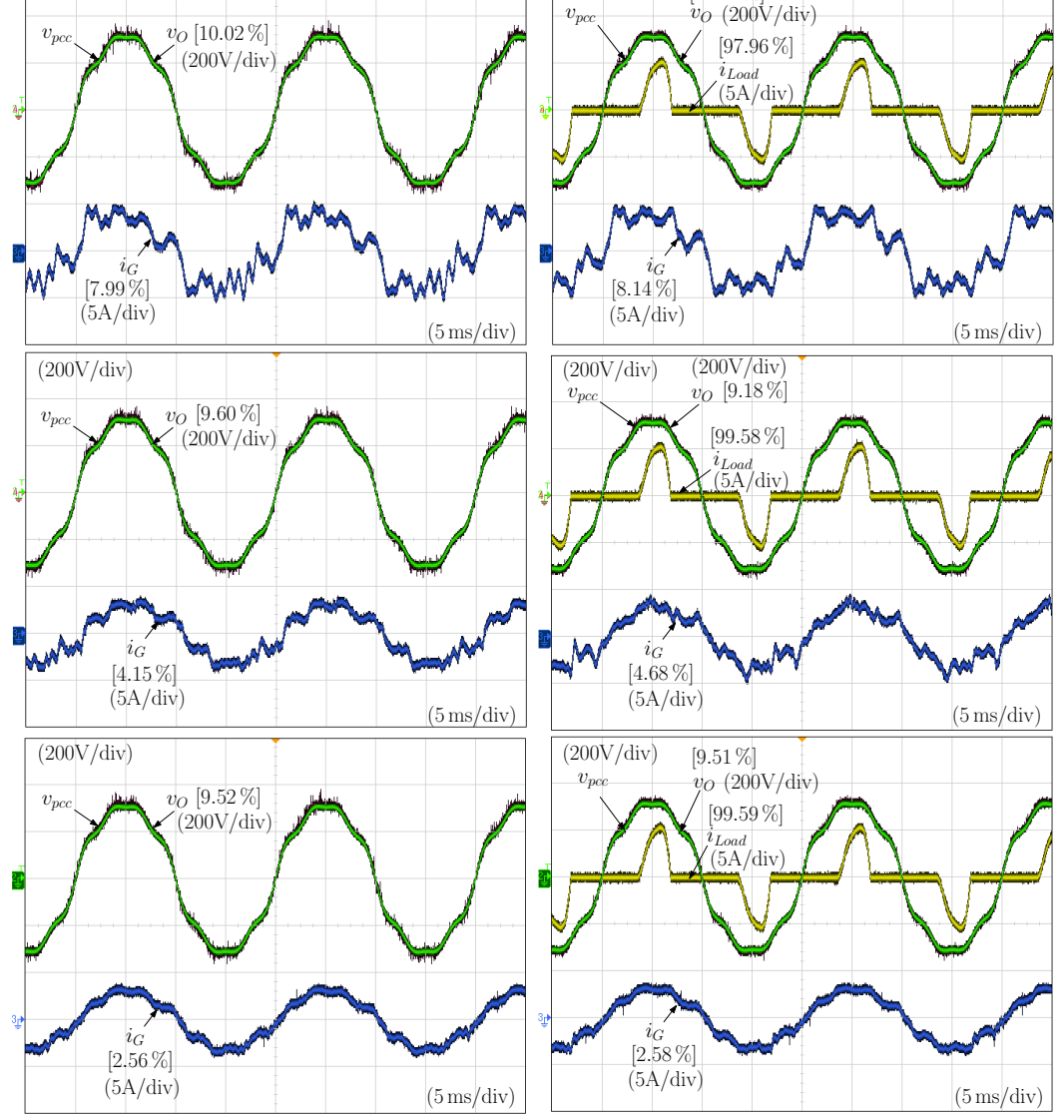

test condition $b$ )

test condition $c$ )

Fig. 8. Inverter performance under: a) ideal grid voltage, b) harmonic polluted grid voltage, c) polluted grid voltage with local distorting load. 
TABLE III

IMPLEMENTED CONTROLLERS FOR THE TESTS OF FIG. 8

\begin{tabular}{c|c|c|c|c|c}
\hline \hline \multirow{2}{*}{ Loop } & Controller structure & \multirow{2}{*}{ Schematic } & \multicolumn{3}{|c}{ Regulators (inner - outer) } \\
\cline { 4 - 6 } & (inner - outer) & & Types & Control equations & Control loop parameters \\
\hline Single & $i_{L}$ & Fig.2 & DB & $(4)$ & {$\left[1 /\left(2 f_{s}\right)\right]$} \\
\hline \multirow{3}{*}{ Double } & $i_{C}-i_{G}$ & Fig.3 (b) & P-PI & $K_{A D}-(6)$ & $1-[$ Maximum bandwidth] \\
\cline { 2 - 5 } & $i_{L}-v_{O}$ & Fig.3 (a) & DB-DB & $(4)-(5)$ & {$\left[1 /\left(2 f_{s}\right)\right]-\left[1 / f_{s}\right]$} \\
\cline { 2 - 5 } & $i_{L}-i_{G}$ & Fig.3 (a) & DB-PI & $(4)-(6)$ & {$\left[1 /\left(2 f_{s}\right)\right]-[$ Maximum bandwidth] } \\
\cline { 2 - 5 } & $v_{O}-i_{G}$ & Fig.3 (c) & DB-PI & $(5)-(6)$ & {$\left[1 / f_{s}\right]-[$ Maximum bandwidth] } \\
\hline Triple & $i_{L}-v_{O}-i_{G}$ & Fig.4 (a) & DB-DB-PI & $(4)-(5)-(6)$ & {$\left[1 /\left(2 f_{s}\right)\right]-\left[1 / f_{s}\right]-[$ Maximum bandwidth] } \\
\hline \hline
\end{tabular}

TABLE IV

MEASURED THD VALUES IN TEST CONDITION $b$ )

\begin{tabular}{c|c|c|c}
\hline \hline \multirow{2}{*}{ Loop } & \multirow{2}{*}{ Controller structure } & \multicolumn{2}{|c}{ Distorted grid } \\
\cline { 2 - 3 } & & $\operatorname{THD}_{v_{O}}$ & $\operatorname{THD}_{i_{G}}$ \\
\hline Single & $i_{L}$ & $9.88 \%$ & $9.03 \%$ \\
\hline \multirow{3}{*}{ Double } & $i_{C}-i_{G}$ & $9.26 \%$ & $8.57 \%$ \\
\cline { 2 - 4 } & $i_{L}-v_{O}$ & $6.24 \%$ & $54.84 \%$ \\
\cline { 2 - 4 } & $i_{L}-i_{G}$ & $10.02 \%$ & $7.99 \%$ \\
\cline { 2 - 4 } & $v_{O}-i_{G}$ & $9.60 \%$ & $4.15 \%$ \\
\hline Triple & $i_{L}-v_{O}-i_{G}$ & $9.52 \%$ & $2.56 \%$ \\
\hline \hline
\end{tabular}

$\operatorname{THD}_{v_{O}}, \mathrm{THD}_{i_{G}}$ calculated with respect to nominal values $V_{N}, I_{N}$.

TABLE V

MEASURED THD VALUES IN TEST CONDITION $C$ )

\begin{tabular}{c|c|c|c|c}
\hline \hline \multirow{2}{*}{ Loop } & \multirow{2}{*}{ Controller structure } & \multicolumn{3}{|c}{ Non-linear load + distorted grid } \\
\cline { 2 - 5 } & $\mathrm{THD}_{i_{L \text { oad }}}$ & $\mathrm{THD}_{v_{O}}$ & $\mathrm{THD}_{i_{G}}$ \\
\hline Single & $i_{L}$ & $92.33 \%$ & $10.12 \%$ & $15.57 \%$ \\
\hline \multirow{3}{*}{ Double } & $i_{C}-i_{G}$ & $95.91 \%$ & $10.31 \%$ & $9.76 \%$ \\
\cline { 2 - 5 } & $i_{L}-v_{O}$ & $105.77 \%$ & $6.29 \%$ & $54.99 \%$ \\
\cline { 2 - 5 } & $i_{L}-i_{G}$ & $97.96 \%$ & $12.11 \%$ & $8.14 \%$ \\
\cline { 2 - 5 } & $v_{O}-i_{G}$ & $99.58 \%$ & $9.18 \%$ & $4.68 \%$ \\
\hline Triple & $i_{L}-v_{O}-i_{G}$ & $99.59 \%$ & $9.51 \%$ & $2.58 \%$ \\
\hline \hline
\end{tabular}

with $i_{C}-i_{G}$ control connected to a real grid, b) represents the same converter in islanded conditions, while connected to an inductive impedance $Z_{g}$ of high magnitude (the considered value is the one measured at the output of a transformer with compatible ratings while open circuited at the primary side due to protection tripping), c) is the basic case of the masterslave microgrid architecture mentioned in Sec. III-A2, where a grid-forming [15] inverter, implemented with $i_{L}-v_{O}$ control, supplies a grid-feeding converter with $i_{C}-i_{G}$ control, d) is the same as the previous case, but with grid-feeding converter with

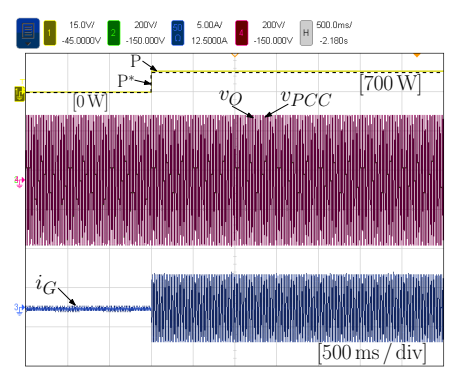

(a) case $i$ )

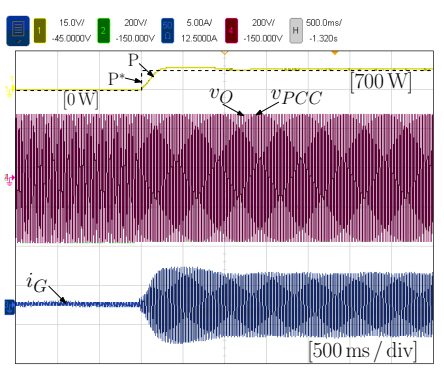

(b) case ii)
Fig. 9. Dynamic response of power flow control.

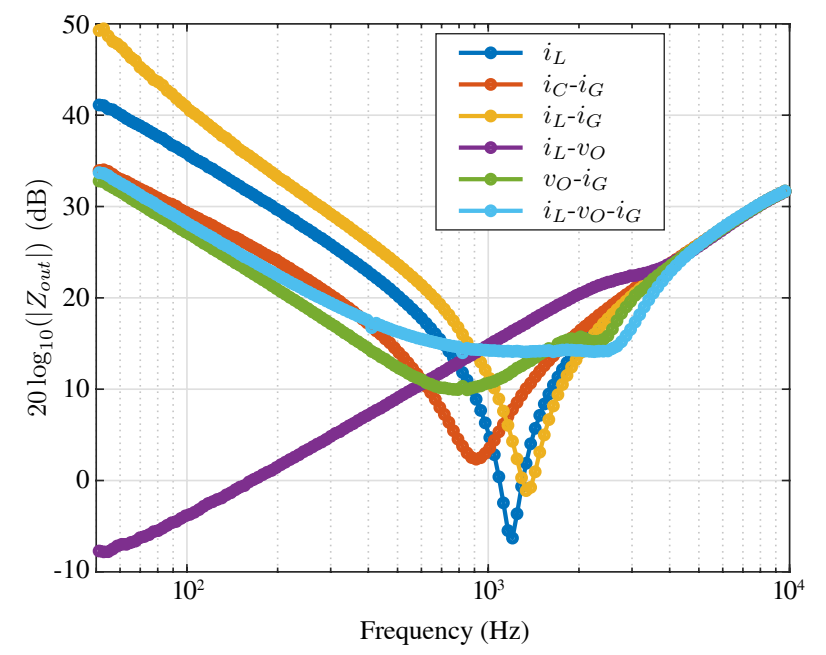

Fig. 10. Measured output impedance in the range from $50 \mathrm{~Hz}$ to $10 \mathrm{kHz}$.

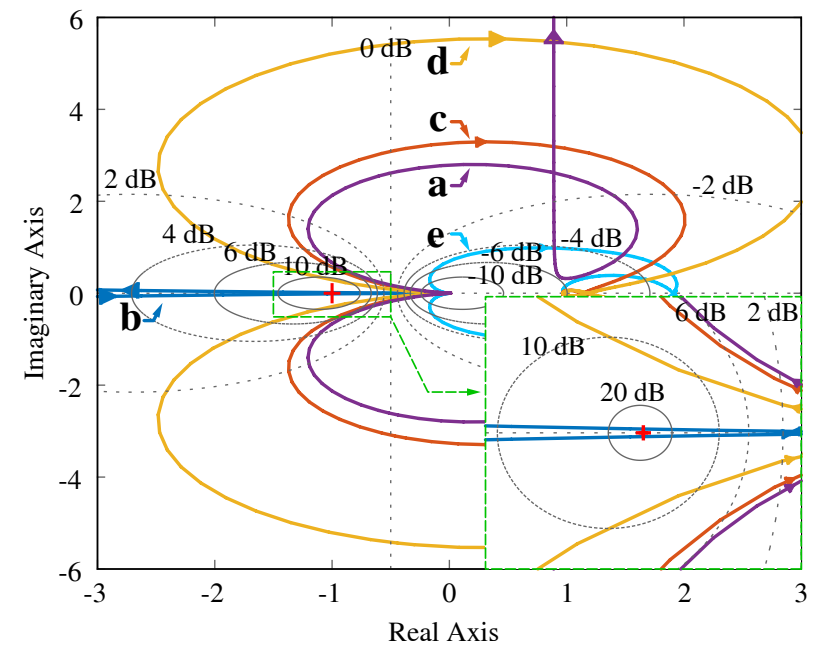

Fig. 11. Nyquist plot of: a) inverter with $i_{C}-i_{G}$ control grid-tied with $Z_{p c c}=Z_{g}=0.1 \Omega+0.5 \mathrm{mH}$, b) islanded inverter with $i_{C}-i_{G}$ control and $Z_{g}=300 \mathrm{mH}, \mathrm{c}$ ) islanded parallel connection of inverter with $i_{C}-i_{G}$ and inverter with $i_{L}-v_{O}$ control, d) islanded parallel connection of inverter with $i_{L}$ and inverter with $i_{L}-v_{O}$ control, e) islanded parallel connection of inverter with $i_{L}-v_{O}-i_{G}$ and inverter with $i_{L}-v_{O}$ control. 
$i_{L}$ control, e) is the same as the previous case, but with gridfeeding converter with $i_{L}-v_{O}-i_{G}$ control. As expected, while referring to Fig. 10, $i_{C}-i_{G}$ shows better stability margins than the $i_{L}$ control while connected to a voltage source, being it the grid or a voltage-controlled inverter with $i_{L}-v_{O}$ control. Overall better performance are shown by the $i_{L}-v_{O}-i_{G}$ control.

\section{FUTURE TRENDS}

Power-electronics dominated low-voltage grids represent a variegate scenario, still in a conceptual and technical evolution. As a result, different unsolved technical challenges will be attracting significant interest, in both research and application, in the near future. Some of the most relevant ones are briefly discussed in the following.

- Grid regulation codes are continuously evolving and steadily widening the functions demanded to grid-tied inverters. This naturally calls for additional sensors and computational performance integration. Resources for zero-level control implementation are expected to increase accordingly, providing a larger amount of information and the chance for even more complex relations with upper control layer functionalities. This will certainly provide a lot of opportunities for new control and management strategies to be developed.

- There are still no clear indications whether to prefer voltage controlled, grid-forming or current controlled, grid-feeding [15] inverter configurations in large scale power systems. Virtual synchronous machines and inertial emulation [161] are important functions that can be based on both the organizations. Which set of controllers can be the most favorable for these implementations is still an open issue.

- Stability enhancement functionalities are crucial in power-electronics dominated grids. One of the most popular methods to damp systems interactions is impedance emulation and passivity-based design [162], for both of which current-controlled structures showed to be effective. However, there is no solid design methodology to attain the desired output impedance shaping. To this purpose, hardware and software co-design, leading to intrinsically damped solutions and taking into account both zero-level control and primary control, brought interesting results in the dc grid domain [163]. Valuable results may be obtained from their application in ac systems too.

- In addition to the consolidated linear control methodologies, non-linear methodologies like the model-predictive controls are emerging in some specific applications. Aspects like control performance merits, setting of optimization goals, and development of algorithms with low computational burden, require additional investigations to allow practical implementations in the low-voltage grid interface application field. Even more so if the integration of upper-level functionalities, like mode transitions and operation during faults, is taken into account.

- The use of wide band-gap devices in grid-tied applications allows to increase switching frequencies and reduce modulation and control delays. Multi-loop structures may benefit from reduced delays and call for further modeling and analysis to meet future needs and control capabilities. At the PCC of the microgrid with the upstream grid, a direct connection with the medium voltage distribution infrastructure could also be enabled by this new switch technology, where multi-level converters are used in place of traditional distribution transformers. From this perspective, new protection and regulation means are required to preserve the features of traditional transformers and ensure a stable operation also during faults.

- The microgrid environment is a very variable and automatized environment, where resources, loads, and electromechanical devices can plug-\&-play connect and disconnect and the distribution grid may reconfigure in response to specific events. The ability of controllers to adapt to the changing conditions is crucial to ensure good performance in the widest possible range of conditions. Auto-tuning techniques are valuable tools from this respect, but have to face the challenge of the multiple converter scenario, where the tuning processes should not be impaired by other converters operating simultaneously.

\section{CONCLUSIONS}

This paper provides an overview of existing control strategies for grid-tied inverters used in microgrids and describes the crucial functionalities that these converters should offer. In addition, the paper discusses the feasibility of realizing such functionalities on each type of controller organization. The analysis is verified by a large set of experiments on a $3 \mathrm{kVA}$ grid-tied inverter with $L C L$-filter. The experimental results agree with the analysis and demonstrate that: $i) i_{L}-v_{O}$ controller provides high-quality local voltage, with THD as low as $6.2 \%$ when the grid voltage has $9.9 \%$ THD; ii) $i_{L}-v_{O}-i_{G}$ controller guarantees high-quality injected grid current, with THD as low as $2.58 \%$; iii) $v_{O}-i_{G}$ and $i_{L}-v_{O}-i_{G}$ controllers show better overall performance; $i v$ ) closed-loop control of $i_{L}$ is effective in damping $L C L$ filter resonances, reducing the grid current THD by more than $2 \% ; v$ ) closed-loop control of $v_{O}$ is beneficial for the compensation of harmonics generated by local loads, reducing the grid current THD by almost $4 \%$; $v i$ ) closed-loop control of $i_{G}$ is, in all cases, very effective in attenuating grid current harmonics.

\section{REFERENCES}

[1] S. Bacha, D. Picault et al., "Photovoltaics in Microgrids: An Overview of Grid Integration and Energy Management Aspects," IEEE Ind. Electron. Mag., vol. 9, no. 1, pp. 33-46, Mar. 2015.

[2] D. Burmester, R. Rayudu et al., "A review of nanogrid topologies and technologies," Renewable and Sustain. Energy Reviews, vol. 67, pp. 760-775, 2017.

[3] "IEEE Standard for Interconnection and Interoperability of Distributed Energy Resources with Associated Electric Power Systems Interfaces," IEEE Std 1547-2018, pp. 1-138, Apr. 2018.

[4] S. Sajadian and R. Ahmadi, "Model Predictive Control of Dual-Mode Operations Z-Source Inverter: Islanded and Grid-Connected," IEEE Trans. Power Electron., vol. 33, no. 5, pp. 4488-4497, May. 2018.

[5] Z. Xin, P. Mattavelli et al., "Mitigation of Grid-Current Distortion for LCL-Filtered Voltage-Source Inverter With Inverter-Current Feedback Control," IEEE Trans. Power Electron., vol. 33, no. 7, pp. 6248-6261, Jul. 2018. 
[6] M. Lu, A. Al-Durra et al., "Benchmarking of Stability and Robustness Against Grid Impedance Variation for LCL-Filtered Grid-Interfacing Inverters," IEEE Trans. Power Electron., vol. 33, no. 10, pp. 90339046, Oct. 2018

[7] Q. Liu, T. Caldognetto, and S. Buso, "Stability Analysis and AutoTuning of Interlinking Converters Connected to Weak Grids," IEEE Trans. Power Electron., vol. 34, no. 10, pp. 9435-9446, Oct. 2019.

[8] J. Sun, "Impedance-Based Stability Criterion for Grid-Connected Inverters," IEEE Trans. Power Electron., vol. 26, no. 11, pp. 3075-3078, Nov. 2011.

[9] J. M. Guerrero, J. C. Vasquez et al., "Hierarchical Control of DroopControlled AC and DC Microgrids - A General Approach Toward Standardization," IEEE Trans. Ind. Electron., vol. 58, no. 1, pp. 158172, Jan. 2011.

[10] A. Bidram and A. Davoudi, "Hierarchical Structure of Microgrids Control System," IEEE Trans. Smart Grid, vol. 3, no. 4, pp. 19631976, Dec. 2012

[11] M. H. Cintuglu, T. Youssef, and O. A. Mohammed, "Development and Application of a Real-Time Testbed for Multiagent System Interoperability: A Case Study on Hierarchical Microgrid Control," IEEE Trans. Smart Grid, vol. 9, no. 3, pp. 1759-1768, May. 2018.

[12] J. M. Guerrero, M. Chandorkar et al., "Advanced Control Architectures for Intelligent Microgrids - Part I: Decentralized and Hierarchical Control," IEEE Trans. Ind. Electron., vol. 60, no. 4, pp. 1254-1262, Apr. 2013

[13] L. Meng, M. Savaghebi et al., "Microgrid central controller development and hierarchical control implementation in the intelligent microgrid lab of Aalborg University," in 2015 IEEE Appl. Power Electronics Conf. and Expo. (APEC), pp. 2585-2592, Mar. 2015.

[14] T. L. Vandoorn, J. C. Vasquez et al., "Microgrids: Hierarchical Control and an Overview of the Control and Reserve Management Strategies," IEEE Ind. Electron. Mag., vol. 7, no. 4, pp. 42-55, Dec. 2013.

[15] J. Rocabert, A. Luna et al., "Control of Power Converters in AC Microgrids," IEEE Trans. Power Electron., vol. 27, no. 11, pp. 4734 4749, Nov. 2012.

[16] S. Parhizi, H. Lotfi et al., "State of the Art in Research on Microgrids: A Review," IEEE Access, vol. 3, pp. 890-925, 2015.

[17] Z. Gao, J. Xu et al., "Research Review on the Smart Distribution Grid," in 2018 IEEE Int. Conf. on Mechatronics and Automation (ICMA), pp. 2003-2008, Aug. 2018.

[18] B. M. Eid, N. A. Rahim et al., "Control Methods and Objectives for Electronically Coupled Distributed Energy Resources in Microgrids: A Review," IEEE Systems Journal, vol. 10, no. 2, pp. 446-458, Jun. 2016.

[19] Y. Han, H. Li et al., "Review of Active and Reactive Power Sharing Strategies in Hierarchical Controlled Microgrids," IEEE Trans. Power Electron., vol. 32, no. 3, pp. 2427-2451, Mar. 2017.

[20] T. Samad and A. M. Annaswamy, "Controls for Smart Grids: Architectures and Applications," Proc. IEEE, vol. 105, no. 11, pp. 2244-2261, Nov. 2017.

[21] A. Alfergani, K. A. Alfaitori et al., "Control strategies in AC microgrid: A brief review," in 2018 9th Int. Renewable Energy Congr. (IREC), pp. 1-6, Mar. 2018.

[22] T. Morstyn, B. Hredzak, and V. G. Agelidis, "Control Strategies for Microgrids With Distributed Energy Storage Systems: An Overview," IEEE Trans. Smart Grid, vol. 9, no. 4, pp. 3652-3666, Jul. 2018.

[23] Y. Han, K. Zhang et al., "MAS-Based Distributed Coordinated Control and Optimization in Microgrid and Microgrid Clusters: A Comprehensive Overview," IEEE Trans. Power Electron., vol. 33, no. 8, pp. 6488-6508, Aug. 2018.

[24] T. Wu, G. Bao et al., "A Review for Control Strategies in Microgrid," in 2018 37th Chinese Control Conf. (CCC), pp. 30-35, Jul. 2018.

[25] T. Wang, H. Nian, and Z. Q. Zhu, "Using inverter-based renewable generators to improve the grid power quality - A review," Chinese Journal of Electrical Engineering, vol. 4, no. 4, pp. 16-25, Dec. 2018.

[26] A. Gupta, S. Doolla, and K. Chatterjee, "Hybrid AC-DC Microgrid: Systematic Evaluation of Control Strategies," IEEE Trans. Smart Grid, vol. 9, no. 4, pp. 3830-3843, Jul. 2018.

[27] J. Arai, K. Iba et al., "Power electronics and its applications to renewable energy in Japan," IEEE Circuits and Syst. Mag., vol. 8, no. 3, pp. 52-66, Third 2008.

[28] J. Xu, S. Xie, and T. Tang, "Evaluations of current control in weak grid case for grid-connected LCL-filtered inverter," IET Power Electronics, vol. 6, no. 2, pp. 227-234, Feb. 2013.

[29] R. Panigrahi, S. K. Mishra, and S. C. Srivastava, "Grid Integration of Small-Scale Photovoltaic Systems-A Review," in 2018 IEEE Industry Appl. Society Annu. Meeting (IAS), pp. 1-8, Sep. 2018.
[30] B. Pal, P. K. Sahu, and S. Mohapatra, "A review on feedback current control techniques of grid-connected PV inverter system with LCL filter," in 2018 Technologies for Smart-City Energy Security and Power (ICSESP), pp. 1-6, Mar. 2018.

[31] P. C. Loh and D. G. Holmes, "Analysis of multiloop control strategies for LC/CL/LCL-filtered voltage-source and current-source inverters," IEEE Trans. Ind. Appl., vol. 41, no. 2, pp. 644-654, Mar. 2005.

[32] M. S. Munir, J. He, and Y. W. Li, "Comparative analysis of closed-loop current control of grid connected converter with LCL filter," in 2011 IEEE Int. Electric Machines Drives Conf. (IEMDC), pp. 1641-1646, May. 2011.

[33] J. C. Vasquez, J. M. Guerrero et al., "Hierarchical Control of Intelligent Microgrids," IEEE Ind. Electron. Mag., vol. 4, no. 4, pp. 23-29, Dec. 2010.

[34] T. Abeyasekera, C. M. Johnson et al., "Suppression of line voltage related distortion in current controlled grid connected inverters," IEEE Trans. Power Electron., vol. 20, no. 6, pp. 1393-1401, Nov. 2005.

[35] Y. Tang, P. C. Loh et al., "Exploring Inherent Damping Characteristic of LCL-Filters for Three-Phase Grid-Connected Voltage Source Inverters," IEEE Trans. Power Electron., vol. 27, no. 3, pp. 1433-1443, Mar. 2012.

[36] Y. Tzou, "DSP-based fully digital control of a PWM DC-AC converter for AC voltage regulation," in Proc. PESC '95 - Power Electron. Specialist Conf., vol. 1, pp. 138-144 vol.1, Jun. 1995.

[37] Y. Han, Z. Li, and J. M. Guerrero, "Dynamic evaluation of LCLtype grid-connected inverters with different current feedback control schemes," in 2015 9th Int. Conf. Power Electron. and ECCE Asia (ICPE-ECCE Asia), pp. 391-396, Jun. 2015.

[38] B. Shoeiby, R. Davoodnezhad et al., "Voltage-frequency control of an islanded microgrid using the intrinsic droop characteristics of resonant current regulators," in 2014 IEEE Energy Convers. Congr. and Expo. (ECCE), pp. 68-75, Sep. 2014.

[39] X. Guo, W. Liu, and Z. Lu, "Flexible Power Regulation and CurrentLimited Control of the Grid-Connected Inverter Under Unbalanced Grid Voltage Faults," IEEE Trans. Ind. Electron., vol. 64, no. 9, pp. 7425-7432, Sep. 2017.

[40] Z. Xin, X. Wang et al., "Grid-Current-Feedback Control for LCLFiltered Grid Converters With Enhanced Stability," IEEE Trans. Power Electron., vol. 32, no. 4, pp. 3216-3228, Apr. 2017.

[41] R. Teodorescu, F. Blaabjerg et al., "A new control structure for gridconnected LCL PV inverters with zero steady-state error and selective harmonic compensation," in 19th Annu. IEEE Appl. Power Electron. Conf. and Expo., 2004. APEC '04., vol. 1, pp. 580-586 Vol.1, Feb. 2004.

[42] S. Buso, T. Caldognetto, and D. I. Brandao, "Dead-Beat Current Controller for Voltage-Source Converters With Improved Large-Signal Response," IEEE Trans. Ind. Appl., vol. 52, no. 2, pp. 1588-1596, Mar. 2016.

[43] G. Escobar, M. J. Lopez-Sanchez et al., "Inverter-side current control of a single-phase inverter grid connected trough an LCL filter," in IECON 2014 - 40th Annu. Conf. IEEE Ind. Electron. Society, pp. 5552-5558, Oct. 2014

[44] Q. Yan, X. Wu et al., "An Improved Grid-Voltage Feedforward Strategy for High-Power Three-Phase Grid-Connected Inverters Based on the Simplified Repetitive Predictor," IEEE Trans. Power Electron., vol. 31, no. 5, pp. 3880-3897, May. 2016.

[45] S. Park, C. Chen et al., "Admittance Compensation in Current Loop Control for a Grid-Tie LCL Fuel Cell Inverter," IEEE Trans. Power Electron., vol. 23, no. 4, pp. 1716-1723, Jul. 2008.

[46] P. Mattavelli, "Synchronous-frame harmonic control for highperformance AC power supplies," IEEE Trans. Ind. Appl., vol. 37, no. 3, pp. 864-872, May. 2001.

[47] X. Yuan, W. Merk et al., "Stationary-frame generalized integrators for current control of active power filters with zero steady-state error for current harmonics of concern under unbalanced and distorted operating conditions," IEEE Trans. Ind. Appl., vol. 38, no. 2, pp. 523-532, Mar. 2002.

[48] X. Wang, P. C. Loh, and F. Blaabjerg, "Stability Analysis and Controller Synthesis for Single-Loop Voltage-Controlled VSIs," IEEE Trans. Power Electron., vol. 32, no. 9, pp. 7394-7404, Sep. 2017.

[49] Z. Li, Y. Li et al., "Single-Loop Digital Control of High-Power 400-Hz Ground Power Unit for Airplanes," IEEE Trans. Ind. Electron., vol. 57, no. 2, pp. 532-543, Feb. 2010.

[50] R. Teodorescu, F. Blaabjerg et al., "A stable three-phase LCL-filter based active rectifier without damping," in 38th IAS Annu. Meeting Conf. Record Industry Appl. Conf., 2003., vol. 3, pp. 1552-1557 vol.3, Oct. 2003. 
[51] A. Kouchaki and M. Nymand, "Analytical Design of Passive LCL Filter for Three-Phase Two-Level Power Factor Correction Rectifiers," IEEE Trans. Power Electron., vol. 33, no. 4, pp. 3012-3022, Apr. 2018.

[52] M. Wagner, T. Barth et al., "Discrete-Time Active Damping of LCLResonance by Proportional Capacitor Current Feedback," IEEE Trans. Ind. Appl., vol. 50, no. 6, pp. 3911-3920, Nov. 2014.

[53] J. Dannehl, F. W. Fuchs et al., "Investigation of Active Damping Approaches for PI-Based Current Control of Grid-Connected Pulse Width Modulation Converters With LCL Filters," IEEE Trans. Ind. Appl., vol. 46, no. 4, pp. 1509-1517, Jul. 2010.

[54] J. Dannehl, F. W. Fuchs, and P. B. Th $\phi$ gersen, "PI State Space Current Control of Grid-Connected PWM Converters With LCL Filters," IEEE Trans. Power Electron., vol. 25, no. 9, pp. 2320-2330, Sep. 2010

[55] X. Li, J. Fang et al., "Capacitor-Voltage Feedforward With Full Delay Compensation to Improve Weak Grids Adaptability of LCL-Filtered Grid-Connected Converters for Distributed Generation Systems," IEEE Trans. Power Electron., vol. 33, no. 1, pp. 749-764, Jan. 2018.

[56] W. Yao, Y. Yang et al., "Design and Analysis of Robust Active Damping for LCL Filters Using Digital Notch Filters," IEEE Trans. Power Electron., vol. 32, no. 3, pp. 2360-2375, Mar. 2017.

[57] R. Peña-Alzola, M. Liserre et al., "Systematic Design of the LeadLag Network Method for Active Damping in LCL-Filter Based Three Phase Converters," IEEE Trans. Industrial Informatics, vol. 10, no. 1, pp. 43-52, Feb. 2014.

[58] J. Roldán-Pérez, E. J. Bueno et al., "All-Pass-Filter-Based Active Damping for VSCs With LCL Filters Connected to Weak Grids," IEEE Trans. Power Electron., vol. 33, no. 11, pp. 9890-9901, Nov. 2018.

[59] A. K. Balasubramanian and V. John, "Analysis and design of splitcapacitor resistive inductive passive damping for LCL filters in gridconnected inverters," IET Power Electron., vol. 6, no. 9, pp. 1822-1832, Nov. 2013

[60] N. He, D. Xu et al., "Weighted Average Current Control in a ThreePhase Grid Inverter With an LCL Filter," IEEE Trans. Power Electron., vol. 28, no. 6, pp. 2785-2797, Jun. 2013.

[61] K. S. Alam, M. P. Akter et al., "Asymptotically Stable Predictive Control of Grid-Connected Converter Based on Discrete Space Vector Modulation," IEEE IEEE Trans. Ind. Info., vol. 15, no. 5, pp. 27752785, May. 2019.

[62] P. Acuna, R. P. Aguilera et al., "Cascade-Free Model Predictive Control for Single-Phase Grid-Connected Power Converters," IEEE Trans. Ind. Electron., vol. 64, no. 1, pp. 285-294, Jan. 2017.

[63] X. Li, H. Zhang et al., "Model Predictive Control of a VoltageSource Inverter with Seamless Transition Between Islanded and GridConnected Operations," IEEE Trans. Ind. Electron., vol. 64, no. 10, pp. 7906-7918, Oct. 2017

[64] S. Vazquez, J. I. Leon et al., "Model Predictive Control: A Review of Its Applications in Power Electronics," IEEE Ind. Electron. Mag., vol. 8, no. 1, pp. 16-31, Mar. 2014.

[65] T. Wu, L. Lin et al., "Extended Application of D- $\Sigma$ Digital Control to a Single-Phase Bidirectional Inverter With an LCL Filter," IEEE Trans. Power Electron., vol. 30, no. 7, pp. 3903-3911, Jul. 2015.

[66] S. Buso, S. Fasolo, and P. Mattavelli, "Uninterruptible power supply multiloop control employing digital predictive voltage and current regulators," IEEE Trans. Ind. Appl., vol. 37, no. 6, pp. 1846-1854, Nov. 2001.

[67] X. Wang, F. Blaabjerg et al., "Resonance analysis in parallel voltagecontrolled Distributed Generation inverters," in 2013 28th Annu. IEEE Appl. Power Electron. Conf. and Expo. (APEC), Mar. 2013.

[68] J. He and Y. W. Li, "Analysis, Design, and Implementation of Virtual Impedance for Power Electronics Interfaced Distributed Generation," IEEE Trans. Ind. Appl., vol. 47, no. 6, pp. 2525-2538, Nov. 2011

[69] A. F. Q. Gonçalves, C. R. Aguiar et al., "Voltage and power control used to stabilise the distributed generation system for stand-alone or grid-connected operation," IET Power Electron., vol. 9, no. 3, 2016.

[70] X. Wang, F. Blaabjerg, and Z. Chen, "Synthesis of Variable Harmonic Impedance in Inverter-Interfaced Distributed Generation Unit for Harmonic Damping Throughout a Distribution Network," IEEE Trans. Ind. Appl., vol. 48, no. 4, pp. 1407-1417, Jul. 2012

[71] A. Micallef, M. Apap et al., "Performance comparison for virtual impedance techniques used in droop controlled islanded microgrids," in 2016 Int. Symp. Power Electron., Elect. Drives, Automat. and Motion (SPEEDAM), pp. 695-700, Jun. 2016.

[72] Y. Guan, Y. Wang et al., "The Dual-Current Control Strategy of GridConnected Inverter With LCL Filter," IEEE Trans. Power Electron., vol. 34, no. 6, pp. 5940-5952, Jun. 2019

[73] O. Kukrer, S. Bayhan, and H. Komurcugil, "Model-Based Current Control Strategy With Virtual Time Constant for Improved Dynamic
Response of Three-Phase Grid-Connected VSI," IEEE Trans. Ind. Electron., vol. 66, no. 6, pp. 4156-4165, Jun. 2019.

[74] S. Yang, Q. Lei et al., "A Robust Control Scheme for Grid-Connected Voltage-Source Inverters," IEEE Trans. Ind. Electron., vol. 58, no. 1, pp. 202-212, Jan. 2011

[75] A. Papavasiliou, S. A. Papathanassiou et al., "Current Control of a Voltage Source Inverter Connected to the Grid via LCL Filter," in 2007 IEEE Power Electron. Specialists Conf., pp. 2379-2384, Jun. 2007.

[76] J. He and B. Liang, "Selective harmonic compensation using active power filter with enhanced double-loop controller," in 2016 IEEE 8th Int. Power Electron. and Motion Control Conf. (IPEMC-ECCE Asia), pp. 2714-2718, May. 2016.

[77] H. Komurcugil, S. Bayhan, and H. Abu-Rub, "Variable- and FixedSwitching-Frequency-Based HCC Methods for Grid-Connected VSI With Active Damping and Zero Steady-State Error," IEEE Trans. Ind. Electron., vol. 64, no. 9, pp. 7009-7018, Sep. 2017.

[78] D. Pan, X. Ruan et al., "Capacitor-Current-Feedback Active Damping With Reduced Computation Delay for Improving Robustness of LCLType Grid-Connected Inverter," IEEE Trans. Power Electron., vol. 29, no. 7, pp. 3414-3427, Jul. 2014.

[79] Erika Twining and D. G. Holmes, "Grid current regulation of a threephase voltage source inverter with an LCL input filter," IEEE Trans. Power Electron., vol. 18, no. 3, pp. 888-895, May. 2003.

[80] M. B. Saïd-Romdhane, M. W. Naouar et al., "Robust Active Damping Methods for LCL Filter-Based Grid-Connected Converters," IEEE Trans. Power Electron., vol. 32, no. 9, pp. 6739-6750, Sep. 2017.

[81] Z. Zou, Z. Wang, and M. Cheng, "Modeling, Analysis, and Design of Multifunction Grid-Interfaced Inverters With Output LCL Filter," IEEE Trans. Power Electron., vol. 29, no. 7, pp. 3830-3839, Jul. 2014.

[82] X. Duan and H. Zhang, "Quasi-proportional resonant control of the LCL-type grid-connected inverter based on fuzzy control and selftuning of fuzzy parameters," in 2017 29th Chinese Control and Decision Conf. (CCDC), pp. 1793-1797, May. 2017.

[83] Q. Zhong and T. Hornik, "Cascaded Current Voltage Control to Improve the Power Quality for a Grid-Connected Inverter With a Local Load," IEEE Trans. Ind. Electron., vol. 60, no. 4, pp. 1344-1355, Apr 2013.

[84] Z. Xin, X. Wang et al., "Realization of Digital Differentiator Using Generalized Integrator For Power Converters," IEEE Trans. Power Electron., vol. 30, no. 12, pp. 6520-6523, Dec. 2015.

[85] X. Wang, P. C. Loh, and F. Blaabjerg, "A unified grid current control for grid-interactive DG inverters in microgrids," in 2015 9th Int. Conf. Power Electron. and ECCE Asia (ICPE-ECCE Asia), pp. 1483-1490, Jun. 2015.

[86] S. Buso, T. Caldognetto, and Q. Liu, "Analysis and Experimental Characterization of a Large-Bandwidth Triple-Loop Controller for Grid-Tied Inverters," IEEE Trans. Power Electron., vol. 34, no. 2, pp. 1936-1949, Feb. 2019.

[87] P. Tenti, T. Caldognetto et al., "Control of utility interfaces in low voltage microgrids," in 2014 IEEE 5th Int. Symp. Power Electron. for Distributed Generation Systems (PEDG), pp. 1-8, Jun. 2014.

[88] Q. Huang and K. Rajashekara, "A unified selective harmonic compensation strategy using DG-interfacing inverter in both grid-connected and islanded microgrid," in 2017 IEEE Energy Convers. Congr. and Expo. (ECCE), pp. 1588-1593, Oct. 2017.

[89] J. He and B. Liang, "Direct microgrid harmonic current compensation and seamless operation mode transfer using coordinated tripleloop current-voltage-current controller," in 2016 IEEE 8th Int. Power Electron. and Motion Control Conf. (IPEMC-ECCE Asia), pp. 26902693, May. 2016.

[90] Z. Yao, L. Xiao, and Y. Yan, "Seamless Transfer of Single-Phase Grid-Interactive Inverters Between Grid-Connected and Stand-Alone Modes," IEEE Trans. Power Electron., vol. 25, no. 6, pp. 1597-1603, Jun. 2010.

[91] J. He and Y. W. Li, "Hybrid Voltage and Current Control Approach for DG-Grid Interfacing Converters With LCL filters," IEEE Trans. Ind. Electron., vol. 60, no. 5, pp. 1797-1809, May. 2013.

[92] J. He, Y. W. Li, and F. Blaabjerg, "Flexible Microgrid Power Quality Enhancement Using Adaptive Hybrid Voltage and Current Controller,' IEEE Trans. Ind. Electron., vol. 61, no. 6, pp. 2784-2794, Jun. 2014.

[93] J. He, B. Liang et al., "Simultaneous Microgrid Voltage and Current Harmonics Compensation Using Coordinated Control of DualInterfacing Converters," IEEE Trans. Power Electron., vol. 32, no. 4, pp. 2647-2660, Apr. 2017.

[94] Z. Liu and J. Liu, "Indirect Current Control Based Seamless Transfer of Three-phase Inverter in Distributed Generation," IEEE Trans. Power Electron., vol. 29, no. 7, pp. 3368-3383, Jul. 2014. 
[95] H. Li and Y. Xu, "Effects of different control strategies of distributed generation on the equivalent output impedance of the grid-connected inverter," in 2014 16th Int. Conf. Harmonics and Quality of Power (ICHQP), pp. 664-668, May. 2014.

[96] Y. A. I. Mohamed and E. F. El-Saadany, "A Robust Natural-FrameBased Interfacing Scheme for Grid-Connected Distributed Generation Inverters," IEEE Trans. Energy Convers., vol. 26, no. 3, pp. 728-736, Sep. 2011.

[97] J. M. Espi, J. Castello et al., "An Adaptive Robust Predictive Current Control for Three-Phase Grid-Connected Inverters," IEEE Trans. Ind. Electron., vol. 58, no. 8, pp. 3537-3546, Aug. 2011.

[98] L. Corradini, W. Stefanutti, and P. Mattavelli, "Analysis of Multisampled Current Control for Active Filters," IEEE Trans. Ind. Appl., vol. 44, no. 6, pp. 1785-1794, Nov. 2008.

[99] D. Yang, X. Ruan, and H. Wu, "A Real-Time Computation Method With Dual Sampling Mode to Improve the Current Control Performance of the LCL-Type Grid-Connected Inverter," IEEE Trans. Ind. Electron., vol. 62, no. 7, pp. 4563-4572, Jul. 2015.

[100] L. Zhou, X. Zhou et al., "Inverter-Current-Feedback ResonanceSuppression Method for LCL-Type DG System to Reduce ResonanceFrequency Offset and Grid-Inductance Effect," IEEE Trans. Ind. Electron., vol. 65, no. 9, pp. 7036-7048, Sep. 2018.

[101] X. Wang, F. Blaabjerg, and P. C. Loh, "Grid-Current-Feedback Active Damping for LCL Resonance in Grid-Connected Voltage-Source Converters," IEEE Trans. Power Electron., vol. 31, no. 1, pp. 213-223, Jan. 2016.

[102] X. Zhou, L. Zhou et al., "Robust Grid-Current-Feedback Resonance Suppression Method for LCL-Type Grid-Connected Inverter Connected to Weak Grid," IEEE Trans. Emerg. Sel. Topics Power Electron., vol. 6, no. 4, pp. 2126-2137, Dec. 2018.

[103] F. Liu, Y. Zhou et al., "Parameter Design of a Two-Current-Loop Controller Used in a Grid-Connected Inverter System With LCL Filter," IEEE Trans. Ind. Electron., vol. 56, no. 11, pp. 4483-4491, Nov. 2009.

[104] R. Turner, S. Walton, and R. Duke, "Robust High-Performance Inverter Control Using Discrete Direct-Design Pole Placement," IEEE Trans. Ind. Electron., vol. 58, no. 1, pp. 348-357, Jan. 2011.

[105] "Photovoltaic (PV) Systems - Characteristics of the Utility Interface," IEC 61727-2004, 2004.

[106] "IEEE Draft Standard for the Specification of Microgrid Controllers," IEEE P2030.7/D11, August 2017, pp. 1-42, Jan. 2017.

[107] "Recommended Practice for Utility Interface of Photovoltaic Systems," IEEE Std 929-2000, 2000.

[108] "Rule 21 Generating Facility Interconnections," California Public Utilities Commission (CPUC), 2014.

[109] "Power Generation Systems Connected to the Low-Voltage Distribution Network-Technical Minimum Requirements for the Connection to and Parallel Operation With Low-Voltage Distribution Networks," Assoc. Elect., Electron. and Inf. Technol. (VDE), 2011.

[110] T. Strasser, F. Andrén et al., "A Review of Architectures and Concepts for Intelligence in Future Electric Energy Systems," IEEE Trans. Ind. Electron., vol. 62, no. 4, pp. 2424-2438, Apr. 2015.

[111] B. Olek and M. Wierzbowski, "Local Energy Balancing and Ancillary Services in Low-Voltage Networks With Distributed Generation, Energy Storage, and Active Loads," IEEE Trans. Ind. Electron., vol. 62, no. 4, pp. 2499-2508, Apr. 2015.

[112] M. Debouza and A. Al-Durra, "Grid Ancillary Services From Doubly Fed Induction Generator-Based Wind Energy Conversion System: A Review," IEEE Access, vol. 7, pp. 7067-7081, 2019.

[113] IEEE Std 1204-1997: IEEE Guide for Planning DC Links Terminating at AC Locations Having Low Short-Circuit Capacities. IEEE, 1997.

[114] S. K. Sahoo, A. K. Sinha, and N. K. Kishore, "Control Techniques in AC, DC, and Hybrid AC-DC Microgrid: A Review," IEEE Trans. Emerg. Sel. Topics Power Electron., vol. 6, no. 2, pp. 738-759, Jun. 2018.

[115] X. Zhao, L. Chang et al., "Power system support functions provided by smart inverters-A review," CPSS Trans. Power Electron. and Appl., vol. 3, no. 1, pp. 25-35, Mar. 2018.

[116] X. Fang, S. Misra et al., "Smart Grid - The New and Improved Power Grid: A Survey," IEEE Commun. Surveys Tuts., vol. 14, no. 4, pp. 944-980, Fourth 2012

[117] Y. A. I. Mohamed, "Mitigation of Converter-Grid Resonance, GridInduced Distortion, and Parametric Instabilities in Converter-Based Distributed Generation," IEEE Trans. Power Electron., vol. 26, no. 3, pp. 983-996, Mar. 2011.

[118] F. Nadeem, S. M. S. Hussain et al., "Comparative Review of Energy Storage Systems, Their Roles, and Impacts on Future Power Systems," IEEE Access, vol. 7, pp. 4555-4585, 2019.
[119] A. Reza Malekpour and A. Pahwa, "A Dynamic Operational Scheme for Residential PV Smart Inverters," IEEE Trans. Smart Grid, vol. 8, no. 5, pp. 2258-2267, Sep. 2017.

[120] K. D. Brabandere, B. Bolsens et al., "A Voltage and Frequency Droop Control Method for Parallel Inverters," IEEE Trans. Power Electron. vol. 22, no. 4, pp. 1107-1115, Jul. 2007.

[121] J. C. Vasquez, J. M. Guerrero et al., "Modeling, Analysis, and Design of Stationary-Reference-Frame Droop-Controlled Parallel Three-Phase Voltage Source Inverters," IEEE Trans. Ind. Electron., vol. 60, no. 4, pp. 1271-1280, Apr. 2013.

[122] Q. Zhong, "Robust Droop Controller for Accurate Proportional Load Sharing Among Inverters Operated in Parallel," IEEE Trans. Ind. Electron., vol. 60, no. 4, pp. 1281-1290, Apr. 2013.

[123] J. M. Guerrero, et al., "Output impedance design of parallel-connected UPS inverters with wireless load-sharing control," IEEE Trans. Ind. Electron., vol. 52, no. 4, pp. 1126-1135, Aug. 2005.

[124] H. Zhang, S. Kim et al., "Distributed Adaptive Virtual Impedance Control for Accurate Reactive Power Sharing Based on Consensus Control in Microgrids," IEEE Trans. Smart Grid, vol. 8, no. 4, pp. 1749-1761, Jul. 2017.

[125] J. Kim, J. M. Guerrero et al., "Mode Adaptive Droop Control With Virtual Output Impedances for an Inverter-Based Flexible AC Microgrid," IEEE Trans. Power Electron., vol. 26, no. 3, pp. 689-701, Mar. 2011.

[126] S. Lissandron and P. Mattavelli, "A controller for the smooth transition from grid-connected to autonomous operation mode," in 2014 IEEE Energy Convers. Congr. and Expo. (ECCE), pp. 4298-4305, Sep. 2014.

[127] M. Liserre, F. Blaabjerg, and S. Hansen, "Design and control of an LCL-filter-based three-phase active rectifier," IEEE Trans. Ind. Appl., vol. 41, no. 5, pp. 1281-1291, Sep. 2005.

[128] W. Wu, Y. Liu et al., "Damping Methods for Resonances Caused by LCL-Filter-Based Current-Controlled Grid-Tied Power Inverters: An Overview," IEEE Trans. Ind. Electron., vol. 64, no. 9, pp. 7402-7413, Sep. 2017.

[129] S. G. Parker, B. P. McGrath, and D. G. Holmes, "Regions of Active Damping Control for LCL Filters," IEEE Trans. Ind. Appl., vol. 50, no. 1, pp. 424-432, Jan. 2014.

[130] R. N. Beres, X. Wang et al., "Optimal Design of High-Order PassiveDamped Filters for Grid-Connected Applications," IEEE Trans. Power Electron., vol. 31, no. 3, pp. 2083-2098, Mar. 2016.

[131] J. H. R. Enslin and P. J. M. Heskes, "Harmonic interaction between a large number of distributed power inverters and the distribution network," IEEE Trans. Power Electron., vol. 19, no. 6, pp. 1586-1593, Nov. 2004.

[132] F. Wang, J. L. Duarte et al., "Modeling and Analysis of Grid Harmonic Distortion Impact of Aggregated DG Inverters," IEEE Trans. Power Electron., vol. 26, no. 3, pp. 786-797, Mar. 2011.

[133] J. M. Guerrero, P. C. Loh et al., "Advanced Control Architectures for Intelligent Microgrids-Part II: Power Quality, Energy Storage, and AC/DC Microgrids," IEEE Trans. Ind. Electron., vol. 60, no. 4, pp. 1263-1270, Apr. 2013.

[134] Y. W. Li and J. He, "Distribution System Harmonic Compensation Methods: An Overview of DG-Interfacing Inverters," IEEE Ind. Electron. Mag., vol. 8, no. 4, pp. 18-31, Dec. 2014.

[135] D. M. Vilathgamuwa, P. C. Loh, and Y. Li, "Protection of Microgrids During Utility Voltage Sags," IEEE Trans. Ind. Electron., vol. 53, no. 5 , pp. 1427-1436, Oct. 2006.

[136] A. Benali, M. Khiat et al., "Power Quality Improvement and Low Voltage Ride Through Capability in Hybrid Wind-PV Farms GridConnected Using Dynamic Voltage Restorer," IEEE Access, vol. 6, pp. 68 634-68 648, 2018.

[137] M. Dietmannsberger, F. Grumm, and D. Schulz, "Simultaneous Implementation of LVRT Capability and Anti-Islanding Detection in ThreePhase Inverters Connected to Low-Voltage Grids," IEEE Trans. Energy Convers., vol. 32, no. 2, pp. 505-515, Jun. 2017.

[138] Y. Yang, F. Blaabjerg, and H. Wang, "Low-Voltage Ride-Through of Single-Phase Transformerless Photovoltaic Inverters," IEEE Trans. Ind. Appl., vol. 50, no. 3, pp. 1942-1952, May. 2014.

[139] A. Ghanem, M. Rashed et al., "Grid impedance estimation for islanding detection and adaptive control of converters," in 8th IET Int. Conf. Power Electronics, Machines and Drives (PEMD 2016), pp. 1-6, Apr. 2016.

[140] B. Hoseinzadeh, C. L. Bak, and F. Blaabjerg, "Impact of grid impedance variations on harmonic emission of grid-connected inverters," in 2017 IEEE Manchester PowerTech, pp. 1-5, Jun. 2017. 
[141] D. Pan, X. Ruan et al., "Optimized Controller Design for LCL-Type Grid-Connected Inverter to Achieve High Robustness Against GridImpedance Variation," IEEE Trans. Ind. Electron., vol. 62, no. 3, pp. 1537-1547, Mar. 2015.

[142] J. Xu, S. Xie et al., "Adaptive Feedforward Algorithm Without Grid Impedance Estimation for Inverters to Suppress Grid Current Instabilities and Harmonics Due to Grid Impedance and Grid Voltage Distortion," IEEE Trans. Ind. Electron., vol. 64, no. 9, pp. 7574-7586, Sep. 2017.

[143] J. Xu, S. Xie, and T. Tang, "Improved control strategy with grid-voltage feedforward for LCL-filter-based inverter connected to weak grid," IET Power Electron., vol. 7, no. 10, pp. 2660-2671, 2014.

[144] M. Cespedes and J. Sun, "Adaptive Control of Grid-Connected Inverters Based on Online Grid Impedance Measurements," IEEE Trans. Sustain. Energy, vol. 5, no. 2, pp. 516-523, Apr. 2014.

[145] F. de Bosio, L. A. de S. Ribeiro et al., "Discrete-Time Domain Modeling of Voltage Source Inverters in Standalone Applications: Enhancement of Regulators Performance by Means of Smith Predictor," IEEE Trans. Power Electron., vol. 32, no. 10, pp. 8100-8114, Oct. 2017.

[146] J. M. Guerrero, L. Hang, and J. Uceda, "Control of Distributed Uninterruptible Power Supply Systems," IEEE Trans. Ind. Electron., vol. 55, no. 8, pp. 2845-2859, Aug. 2008.

[147] T. Caldognetto and P. Tenti, "Microgrids Operation Based on MasterSlave Cooperative Control," IEEE Trans. Emerg. Sel. Topics Power Electron., vol. 2, no. 4, pp. 1081-1088, Dec. 2014.

[148] F. Cavazzana, T. Caldognetto et al., "Analysis of Current Control Interaction of Multiple Parallel Grid-Connected Inverters," IEEE Trans. Sustain. Energy, vol. 9, no. 4, pp. 1740-1749, Oct. 2018.

[149] C. Yoon, H. Bai et al., "Harmonic Stability Assessment for Multiparalleled, Grid-Connected Inverters," IEEE Transactions on Sustainable Energy, vol. 7, no. 4, pp. 1388-1397, Oct. 2016.

[150] Q. Liu, T. Caldognetto, and S. Buso, "Flexible Control of Interlinking Converters for DC Microgrids Coupled to Smart AC Power Systems," IEEE Trans. Ind. Electron., vol. 66, no. 5, pp. 3477-3485, May. 2019.

[151] J. C. Vasquez, J. M. Guerrero et al., "Adaptive Droop Control Applied to Voltage-Source Inverters Operating in Grid-Connected and Islanded Modes," IEEE Trans. Ind. Electron., vol. 56, no. 10, pp. 4088-4096, Oct. 2009.

[152] Z. Zeng and W. Shao, "Reconnection of micro-grid from islanded mode to grid-connected mode used sliding Goertzel transform based filter," IET Renewable Power Generation, vol. 11, no. 7, pp. 1041-1048, 2017.

[153] H. J. Kim, E. S. Shin et al., "Smooth Operation Transition Scheme for Stand-Alone Power System With EG and BESS-PV Panels," IEEE Trans. on Smart Grid, vol. 8, no. 4, pp. 2042-2044, Jul. 2017.

[154] M. N. Arafat, A. Elrayyah, and Y. Sozer, "Hybrid droop and current control for seamless transition mode of microgrids," in 2013 IEEE Energytech, pp. 1-6, May. 2013.

[155] G. H. Bode, Poh Chiang Loh et al., "An improved robust predictive current regulation algorithm," IEEE Trans. Ind. Appl., vol. 41, no. 6, pp. 1720-1733, Nov. 2005.

[156] L. Malesani, P. Mattavelli, and S. Buso, "Robust dead-beat current control for PWM rectifiers and active filters," IEEE Trans. Ind. Appl., vol. 35, no. 3, pp. 613-620, May. 1999.

[157] S. Buso and T. Caldognetto, "Rapid Prototyping of Digital Controllers for Microgrid Inverters," IEEE Trans. Emerg. Sel. Topics Power Electron., vol. 3, no. 2, pp. 440-450, Jun. 2015.

[158] Y. Xia and R. Ayyanar, "Adaptive Dc link voltage control scheme for single phase inverters with dynamic power decoupling," in 2016 IEEE Energy Conversion Congress and Exposition (ECCE), pp. 1-7, Sep. 2016.

[159] F. Chen, R. Burgos, and D. Boroyevich, "A Bidirectional HighEfficiency Transformerless Converter With Common-Mode Decoupling for the Interconnection of AC and DC Grids," IEEE Transactions on Power Electronics, vol. 34, no. 2, pp. 1317-1333, Feb. 2019.

[160] R. D. Middlebrook, "Input filter considerations in design and application of switching regulators," in Conf. Rec. IEEE IAS Annu. Meeting, pp. 366-382, 1976.

[161] J. Fang, H. Li et al., "On the Inertia of Future More-Electronics Power Systems," IEEE Trans. Emerg. Sel. Topics Power Electron., 2018.

[162] A. Akhavan, H. R. Mohammadi et al., IEEE Trans. Power Electron., vol. 35, no. 2, pp. 2135-2150, Feb. 2020.

[163] G. Liu, P. Mattavelli, and S. Saggini, "Design of Droop Controllers for Converters in DC Microgrids Towards Reducing Bus Capacitance," in 2018 20th European Conf. Power Electron. and Appl. (EPE'18 ECCE Europe), pp. 1-9, Sep. 2018.

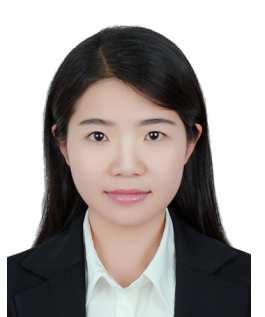

Qing Liu (S'18) received the B.S. and M.S. degrees in electrical engineering from the School of Automation, Northwestern Polytechnical University, China, in 2012 and 2015, respectively. She is currently a Ph.D. student of power electronics with the Department of Information Engineering (DEI) at the University of Padova, Italy. Her main research interests are in the fields of low-voltage microgrids, nano-grids and are particularly related to digital control of power electronic converters.

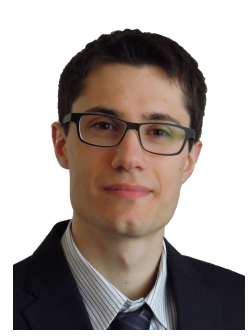

Tommaso Caldognetto (S'10-M'16) received the M.S. (Hons.) degree in electronic engineering and the Ph.D. degree in information engineering from the University of Padova, Italy, in 2012 and 2016, respectively. In 2014, he was a visiting Ph.D. student with the Institute for Automation of Complex Power Systems, University of Aachen, Germany. He is currently a researcher and lecturer with the Department of Technology and Management, University of Padova. $\mathrm{He}$ is a member of the IEEE Power Electronics Society, for which he serves as an Associate Editor for the IEEE Open Journal of Power Electronics. His research interests include control of grid-tied converters, microgrid architectures, and real-time simulation for power electronics.

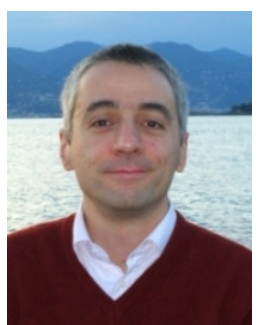

Simone Buso (M'97) received the M.Sc. degree in electronic engineering and the Ph.D. degree in industrial electronics from the University of Padova, Italy, in 1992 and 1997, respectively. He is currently an Associate Professor of electronics with the Department of Information Engineering (DEI) at the University of Padova. His main research interests are in the industrial and power electronics fields and are related specifically to switching converter topologies, digital control of power converters, renewable energy sources 